SANDIA REPORT

SAND97-1630 • UC-406

Unlimited Release

Printed July 1997

\title{
Seafloor Earthquake Measurement System, SEMS IV
}

Mark R. Platzbecker, Joseph P. Ehasz, Ronald J. Franco

Prepared by

Sandia National Laboratories

Albuquerque, New Mexico 87185 and Livermore, California 94550

Sandia is a multiprogram laboratory operated by Sandia

Corporation, a Lockheed Martin Company, for the United States

Department of Energy under Contract DE-AC04-94AL85000.

Approved for public release; distribution is unimited.

\section{Sandia National Laboratories}


Issued by Sandia National Laboratories, operated for the United States Department of Energy by Sandia Corporation.

NOTICE: This report was prepared as an account of work sponsored by an agency of the United States Government. Neither the United States Government nor any agency thereof, nor any of their employees, nor any of their contractors, subcontractors, or their employees, makes any warranty, express or implied, or assumes any legal liability or responsibility for the accuracy, completeness, or usefulness of any information, apparatus, product, or process disclosed, or represents that its use would not infringe privately owned rights. Reference herein to any specific commercial product, process, or service by trade name, trademark, manufacturer, or otherwise, does not necessarily constitute or imply its endorsement, recommendation, or favoring by the United States Government, any agency thereof, or any of their contractors or subcontractors. The views and opinions expressed herein do not necessarily state or reflect those of the United States Government, any agency thereof, or any of their contractors.

Printed in the United States of America. This report has been reproduced directly from the best available copy.

Available to DOE and DOE contractors from

Office of Scientific and Technical Information

P.O. Box 62

Oak Ridge, TN 37831

Prices available from (615) 576-8401, FTS 626-8401

Available to the public from

National Technical Information Service

U.S. Department of Commerce

5285 Port Royal Rd

Springfield, VA 22161

NTIS price codes

Printed copy: A03

Microfiche copy: A01 


\title{
Seafloor Earthquake Measurement System, SEMS IV
}

\author{
Mark R. Platzbecker \\ Joseph P. Ehasz \\ Ronald J. Franco \\ Telemetry Technology Development Department \\ Sandia National Laboratories \\ P. O. Box 5800 \\ Albuquerque, New Mexico 87185-0987
}

\begin{abstract}
Staff of the Telemetry Technology Development Department (2664) have, in support of the U. S. Interior Department Mineral Management Services (MMS), developed and deployed the Seafloor Earthquake Measurement System IV (SEMS IV). The result of this development project is a series of three fully operational seafloor seismic monitor systems located at offshore platforms: Eureka, Grace, and Irene. The instrument probes are embedded from three to seven feet into the seafloor and hardwired to seismic data recorders installed top side at the offshore platforms. The probes and underwater cables were designed to survive the seafloor environment with an operation life of five years. The units have been operational for two years and have produced recordings of several minor earthquakes in that time. Sandia Labs will transfer operation of SEMS IV to MMS contractors in the coming months.
\end{abstract}




\section{Acknowledgments}

The authors thank Charles Smith, Cathy Hoffman, and Leslie Monahan of the Mineral Management Services for project direction and guidance in the SEMS IV development and deployment. Also, we extend our appreciation to the personnel of American Pacific Marine (APM) for providing critical support in devising and implementing the seafloor installation efforts. Further thanks to the management and personnel at Chevron U.S.A. Production Company (platform Grace), Shell West Coast Production Division (platform Eureka), and Torch (platform Irene) for assistance in probe and top side recorder installation. Thanks to Randy Lockhart for mechanical design support. Thanks also to David Ryerson (2664) and Tom Perea (2665) for help in the successful completion of the SEMS IV program. 


\section{DISCLAMMER}

Portions of this document may be illegible in electronic image products. Images are produced from the best available original document. 



\section{Table of Contents}

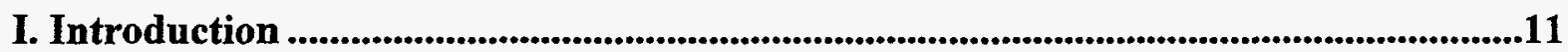

I.1 Project Background ....................................................................................................................11

I.2 SEMS IV Project Objectives ....................................................................................................11

I.3 SEMS IV Operational Status...................................................................................................12

I.4 SEMS IV System Overview ............................................................................................................... 15

II. Measurement Specifications ................................................................................................17

II.1 Data Acquisition and Electrical Specifications .....................................................................17

II.2 Mechanical Specifications ..........................................................................................................18

II.3 Environmental Specifications .............................................................................................................. 18

III. Instrumentation Design and Calibration ..........................................................................18

III.1 Instrumentation Design Overview ................................................................................................ 18

III.2 Instrument Calibration .............................................................................................................20

III.3 Probe Position Sensing from Magnetometer Signals ............................................................. 23

IV. Mechanical Design ...................................................................................................................26

IV.1 Previous Probe Design.......................................................................................................26

IV.2 Lessons Learned; Previous Probe and Previous Installation Process ............................26

IV.3 Current Probe Design............................................................................................................27

V. Installation Procedures.........................................................................................................29

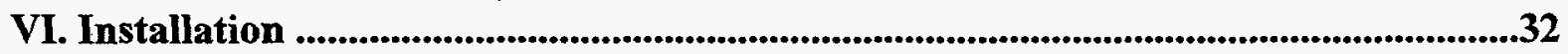

VI.1 Sunday and Monday, July 9 and 10, 1995 ...........................................................................32

VI.2 Tuesday, July 11, 1995_.................................................................................................................33

VI.3 Wednesday, July 12, 1995 .......................................................................................................33

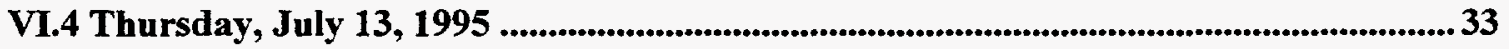

VI.5 Friday, July 14, 1995......................................................................................................34

VII. Functional Testing ...........................................................................................................34

VII.1 Electronics Bench Testing ........................................................................................................34

VII.2 Pressure Testing (Sandia Facility) ................................................................................................34

VII.3 Vibration Testing (APM Facility) .......................................................................................3 34

VIII. Conclusion ...........................................................................................................................35

IX. Appendices .......................................................................................................................37

IX.1 Appendix A. Electronics Schematics and Cabling Pin Outs............................................37

IX.2 Appendix B. Mechanical Fabrication Drawings..................................................................47

IX.3 Appendix C. Navigation Plots....................................................................................................61

IX.4 Appendix D. SEMS IV Operating Instructions .....................................................................64

IX.5 Appendix E. SEMS Accelerometer Orientations....................................................................6 68 
This page intentionally left blank. 


\section{Figures}

Figure I: Earthquake Recorded at Platform Grace, epicenter near Barstow, CA........................13

Figure II: Earthquake Recorded at Platform Irene, epicenter near Ridgecrest, CA ...................14

Figure III: SEMS IV Instrumentation System ............................................................................16

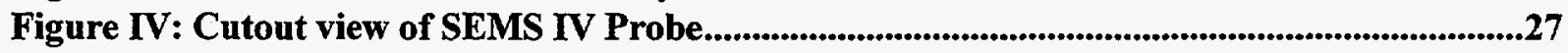

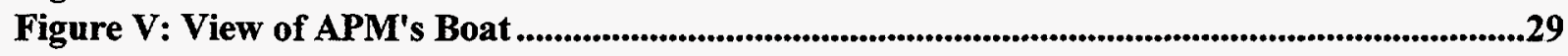

Figure VI: View of Installation Cage as it is lowered over the boat .................................................30

Figure VII: Vibrocorer and coretube hardware....................................................................................31

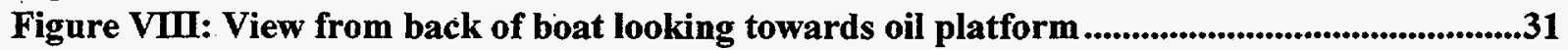

Figure IX: California coast and probe locations .....................................................................................32

Figure X: Probe Electronics Schematic ..............................................................................................38

Figure XI: SEMS IV Control Panel Electronics Schematics.................................................................39

Figure XII: SEMS IV Cable Interconnect Schematic ...........................................................................40

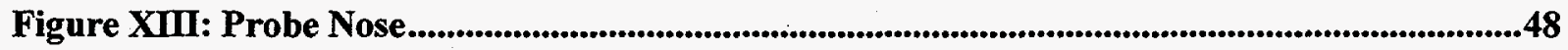

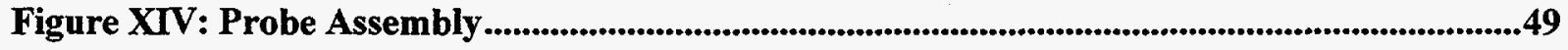

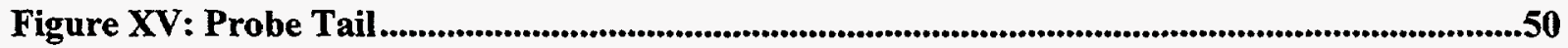

Figure XVI: Cable Cover .....................................................................................................................51

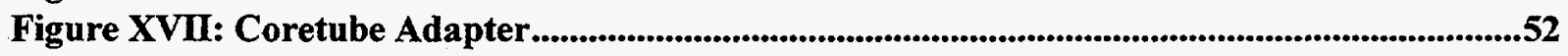

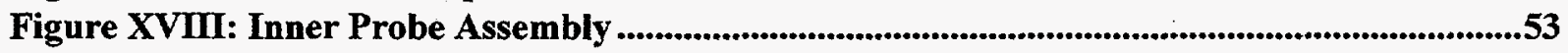

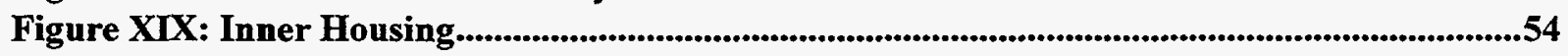

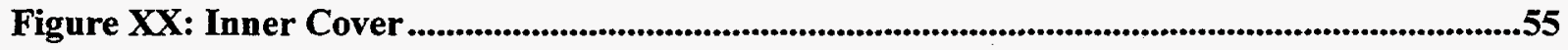

Figure XXI: Connector Plate.........................................................................................................56

Figure XXII: Component Assembly ........................................................................................................57

Figure XXIII: Component Mount......................................................................................................58

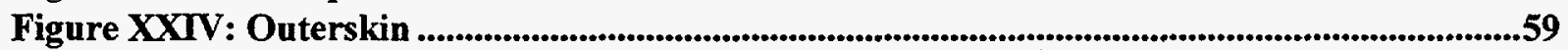

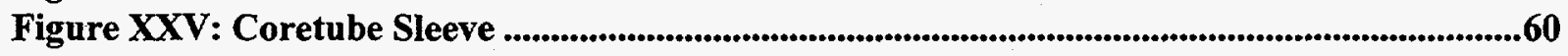

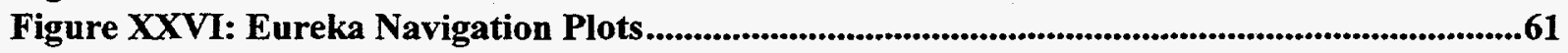

Figure XXVII: Grace Navigation Plots .............................................................................................62

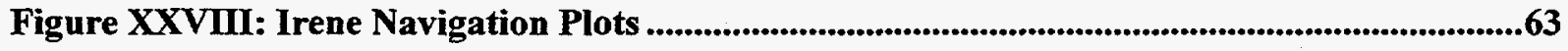

Figure XXIX: SEMS Accelerometer Orientation..............................................................................69 
This page intentionally left blank. 


\section{Tables}

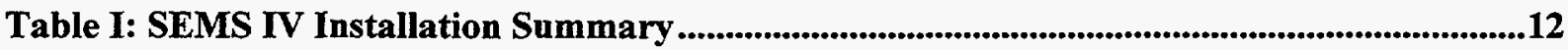

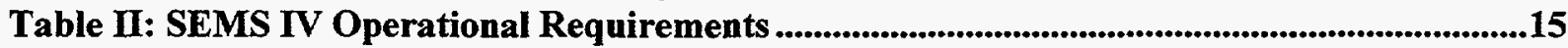

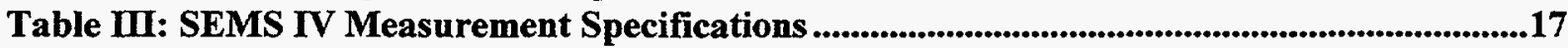

Table IV: SEMS IV Electrical Interface Specifications..........................................................................18

Table V: SEMS IV Underwater Cable Specifications............................................................................20

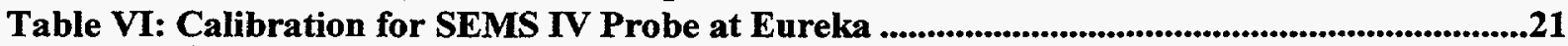

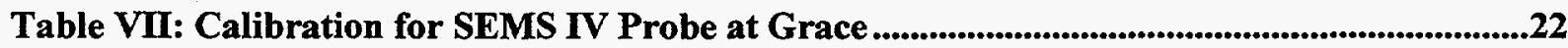

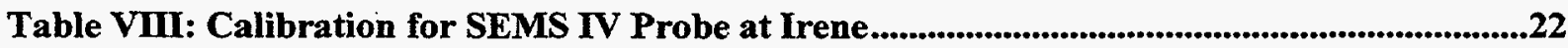

Table IX: Horizontal Axis Magnetometer Calibration for SEMS IV Probes................................24

Table X: Peak Axis Magnetometer Calibration for SEMS IV Probe.................................................24

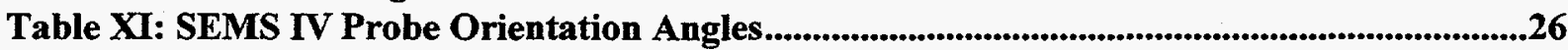

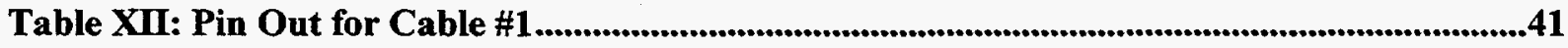

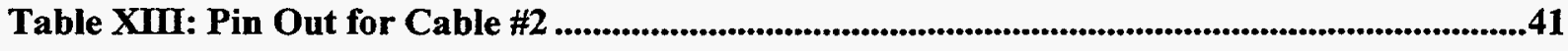

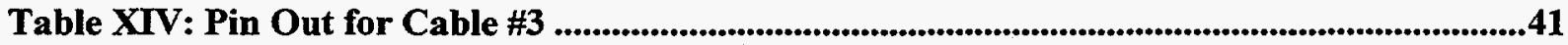

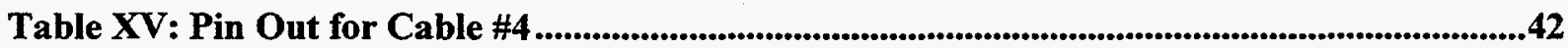

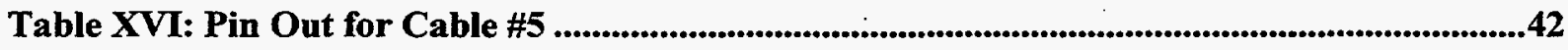

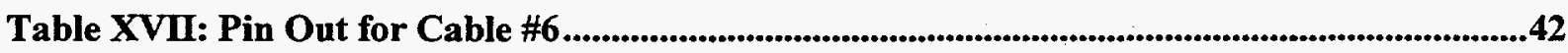

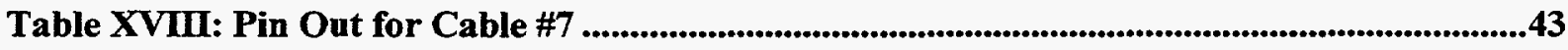

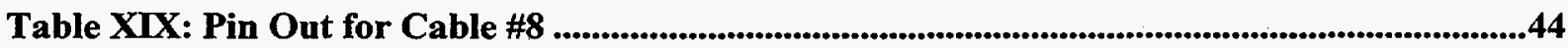

Table XX: Pin Out Internal Control Panel Cable J1 ....................................................................45

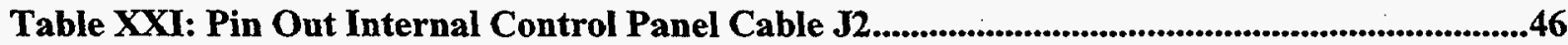

Table XXII: Pin Out Internal Control Panel Cable J3 .......................................................................46

Table XXIII: Nominal State of Health Readings from Platform Eureka ......................................65

Table XXIV: Nominal State-of-Health Readings from Platform Grace ..........................................66

Table XXV: Nominal State-of-Health Readings from Platform Irene ........................................67 
This page intentionally left blank. 


\section{Seafloor Earthquake Measurement System, SEMS IV}

\section{Introduction}

\section{I.1 Project Background}

Sandia Labs and the Mineral Management Services, (U.S. Department of the Interior), have a long history of cooperation in developing seafloor seismic instrumentation. The SEMS IV development follows several previous development efforts dating back to the 1970s. The MMS and Sandia Labs personnel determined in the early 1990s that using a tethered underwater cable to interconnect the seafloor probe to a seismograph on the platform would produce a robust and durable system. The data to be collected will help Mineral Management Services verify and modify soil response models and will aid in the regulation and design of offshore structures in seismically active areas. The instrument probe is embedded in the seafloor, powered through a tethered underwater cable and connected to a commercial seismic recorder mounted on the offshore platforms. This tethered cable approach has been used in the past with mixed results, but the concept is sound. The SEMS IV program was launched in Spring of 1994 to review previous SEMS activities and develop a new instrumentation system.

\section{I.2 SEMS IV Project Objectives}

The primary goal of the SEMS IV development was to develop a mechanically rugged, electrically robust instrument probe to be installed in a tethered configuration. A network of three probes were installed along the southern California coast.

The following major goals were established for the SEMS IV program:

(1) Utilize modern, commercially supplied seismic recorder technology.

(2) Allow for modem access to download event data.

(3) Optimize the probe design and installation process based on lessons learned from previous SEMS activities.

(4) Retain successful elements of previous developments.

(5) Transfer the monitoring and data operations of the sensor array to personnel designated by the MMS.

The SEMS IV program has met goals one through four, and the process of transferring operation of SEMS IV to MMS personnel is under way. 


\section{I.3 SEMS IV Operational Status}

In July 1995, SEMS IV instrument probes were installed at Platforms Eureka, Grace and Irene.

Seismographs and associated power and communication electronics were installed top side at each of the platforms. All three of the units are fully functional and two of the three have recorded earthquakes (Figure I and Figure II.) A memo was released on July 24, 1995 as an initial summary of the SEMS IV installation. Having reviewed the computations for heading and tilt angles (Section III.3), two parameters were found to be slightly in error. The installation summary in Table I corrects those errors and should be used for future reference. Also, note that detailed survey information on the position and underwater cable routing is provided in Appendix C.

Table I: SEMS IV Installation Summary

\begin{tabular}{|l|l|}
\hline Plofform Eureka: \\
\hline Probe Unit \# & SN-01 \\
\hline Insertion Depth (to Nose Tip): & 7 feet \\
\hline Heading Angle: & $37.1^{\circ}$ (East of due North) \\
\hline Tilt Angle: & $2.5^{\circ}$ (from vertical) \\
\hline Water Depth: & 693 feet \\
\hline & \\
\hline Platform Grace: & \\
\hline Probe Unit \# & SN-03 \\
\hline Insertion Depth (to Nose Tip): & 3 feet \\
\hline Heading Angle: & $63.4^{\circ}$ (West of due North) \\
\hline Tilt Angle: & $2.9^{\circ}$ (from vertical) \\
\hline Water Depth: & 318 feet \\
\hline \multicolumn{2}{|l|}{} \\
\hline Platform Irene: & \\
\hline Probe Unit \# & SN-02 \\
\hline Insertion Depth (to Nose Tip): & 5 feet \\
\hline Heading Angle: & $7.3^{\circ}$ (East of due North) \\
\hline Tilt Angle: & $1.1^{\circ}$ (from vertical) \\
\hline Water Depth: & 240 feet \\
\hline & \\
\hline
\end{tabular}

Note: The Heading angle describes orientation of the $+Z$ accelerometer axis to magnetic North 

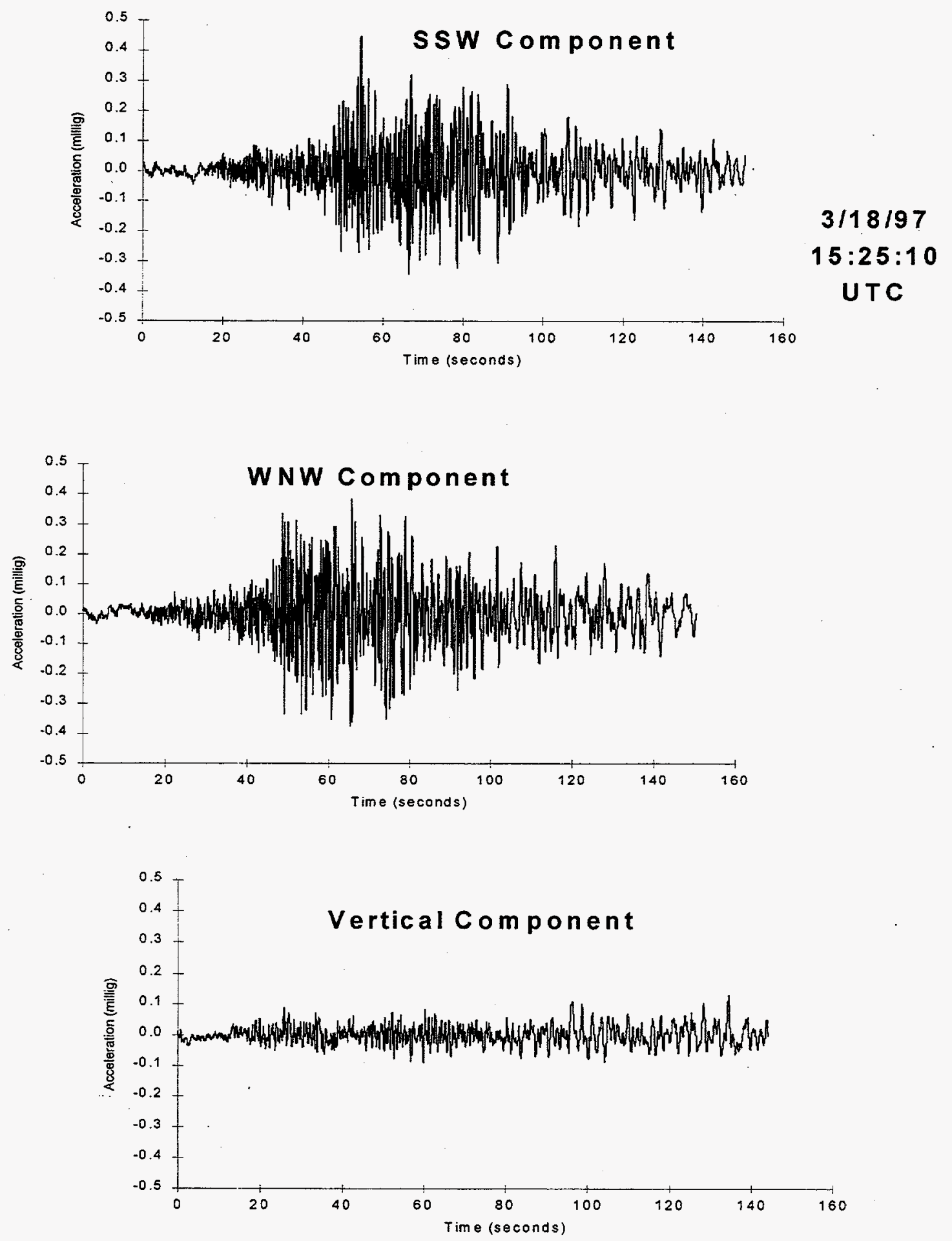

Figure I: Earthquake Recorded at Platform Grace, epicenter near Barstow, CA 

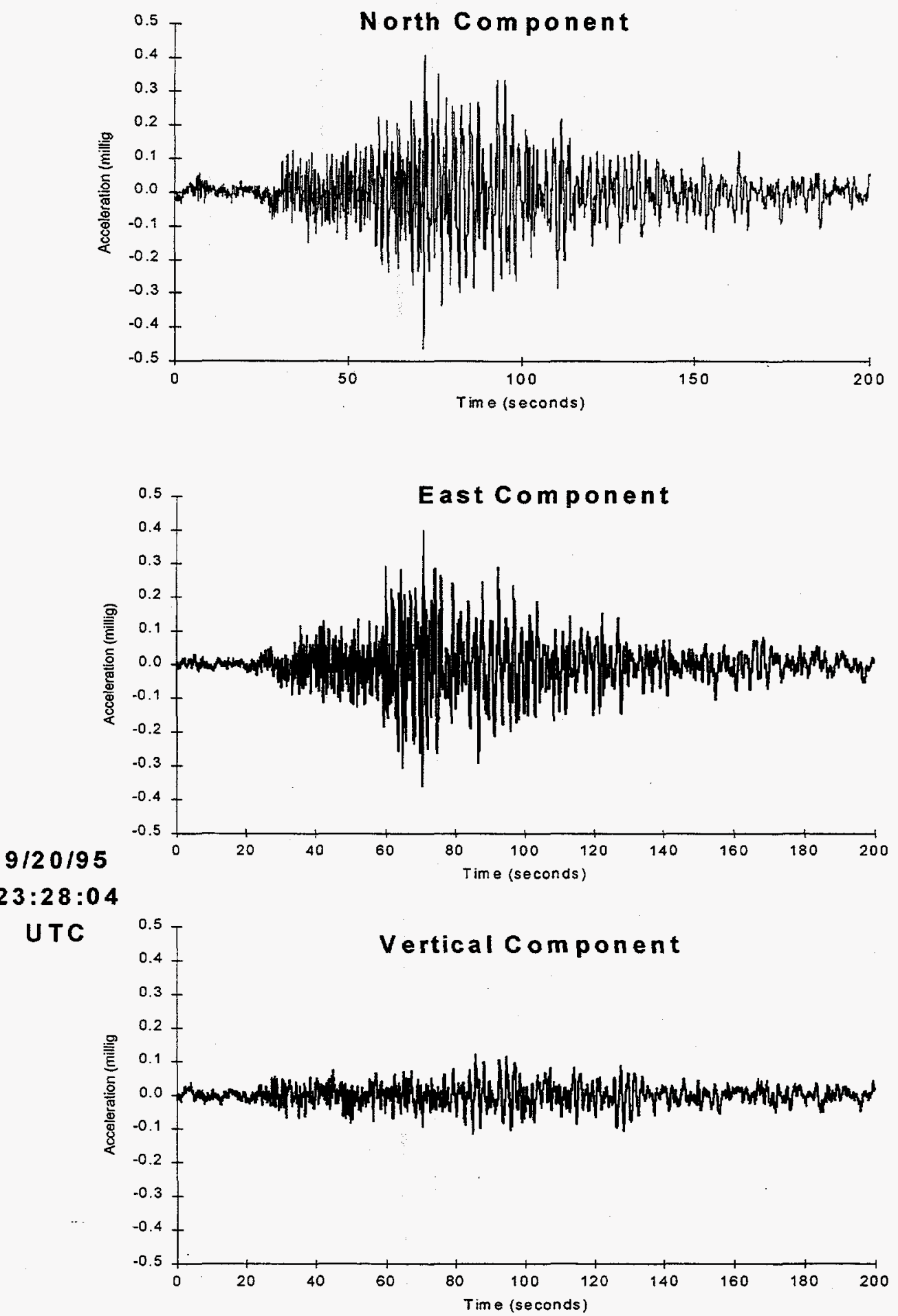

Figure II: Earthquake Recorded at Platform Irene, epicenter near Ridgecrest, CA 


\section{I.4 SEMS IV System Overview}

The SEMS IV instrumentation system was designed to measure three-axis seismic acceleration with high sensitivity and dynamic range. The basic elements of the SEMS IV instrumentation system are shown in Figure III. The event detection and recording is based on the Quanterra Q680/LT-G seismograph. The probe is designed to include only minimal electronics to interface the transducers in the probe to the cable running to the surface. A modem link allows the operators to dial up the Quanterra over standard telephone line to interrogate the recorder for state-of-health or event data down loading. The probe and event recorder are powered directly from the platform power system, but also have backup battery power to allow event recording to continue in the event of power failure. 'The SEMS IV operational requirements provided in Table II represent the requirements negotiated with MMS in project planning for SEMS IV. All of the requirements of Table II were met or exceeded except for the backup battery life requirement. Sandia Labs personnel had identified battery cells which could have met this requirement, but safety considerations on the platforms overruled the use of these cells. For this reason, the twelve-hour backup battery life requirement is not met. The specifications of SEMS IV called out in Table IV indicate backup battery life of 2.8 hours, which should be adequate in most situations. Since the seismograph data is stored statically on a hard disk once an event is detected, no data which was recorded before power loss (or up to 2.8 hours after power loss) would be lost. Only after shock data occurring more than 2.8 hours after power loss could be lost, and some of the platforms have other backup power mechanisms which could recover power before the 2.8 hours of backup life are expended.

Table II: SEMS IV Operational Requirements

\begin{tabular}{|l|l|}
\hline Seismic Measurement Inputs & Three Component Acceleration \\
\hline Seismic Signal Range & $50 \mu \mathrm{g}(\mathrm{rms})$ to $2.8 \mathrm{gs}(\mathrm{rms})$ \\
\hline Seismic Bandwidth & 0.5 to $32 \mathrm{~Hz}$ \\
\hline Position Sensing & $\begin{array}{l}\text { Magnetic heading \& Tilt } \\
\text { Accuracy: } \pm 2.0^{\circ}\end{array}$ \\
\hline Time Correlation & 2.0 msec \\
\hline Data Interface & Remote modem on telephone line \\
\hline Backup Battery Life & 12 hours recording time \\
\hline Data Retention & Fully Static, hard disk \\
\hline Leak Diagnostics & Humidity and Water Contact Sense \\
\hline Operating Depth & $\mathbf{8 0 0}$ feet maximum \\
\hline Operating Life & 5 years minimum in sea water \\
\hline
\end{tabular}




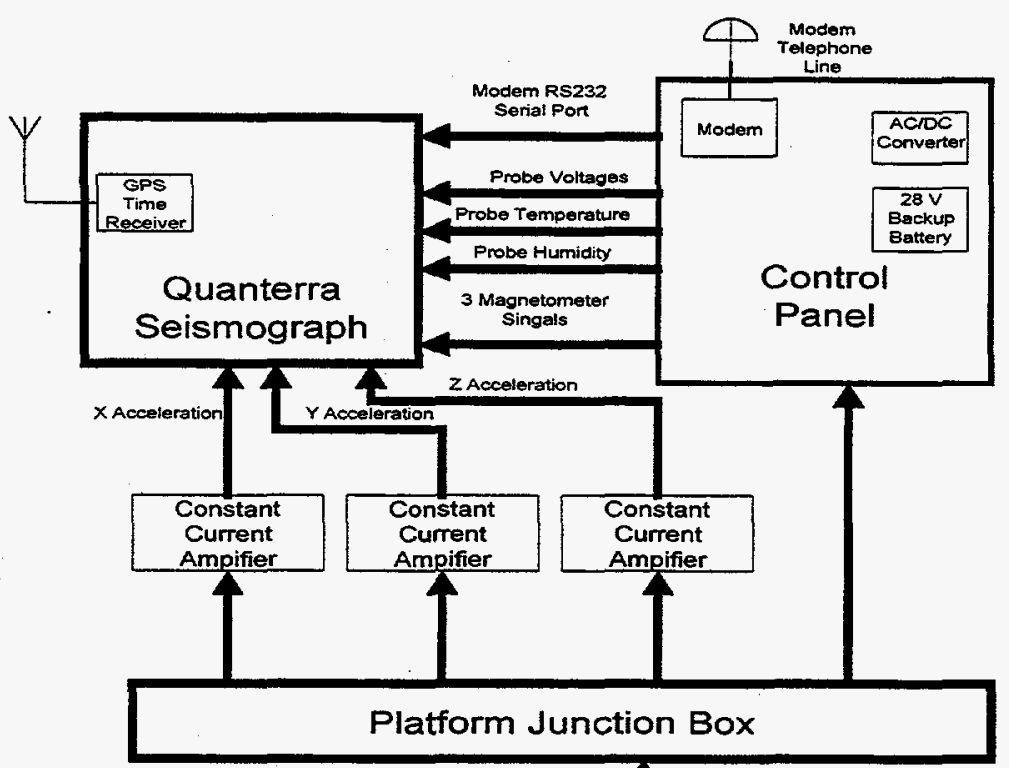

Under Water

Probe Cable ( 400 ' to $800^{\prime}$ Long)

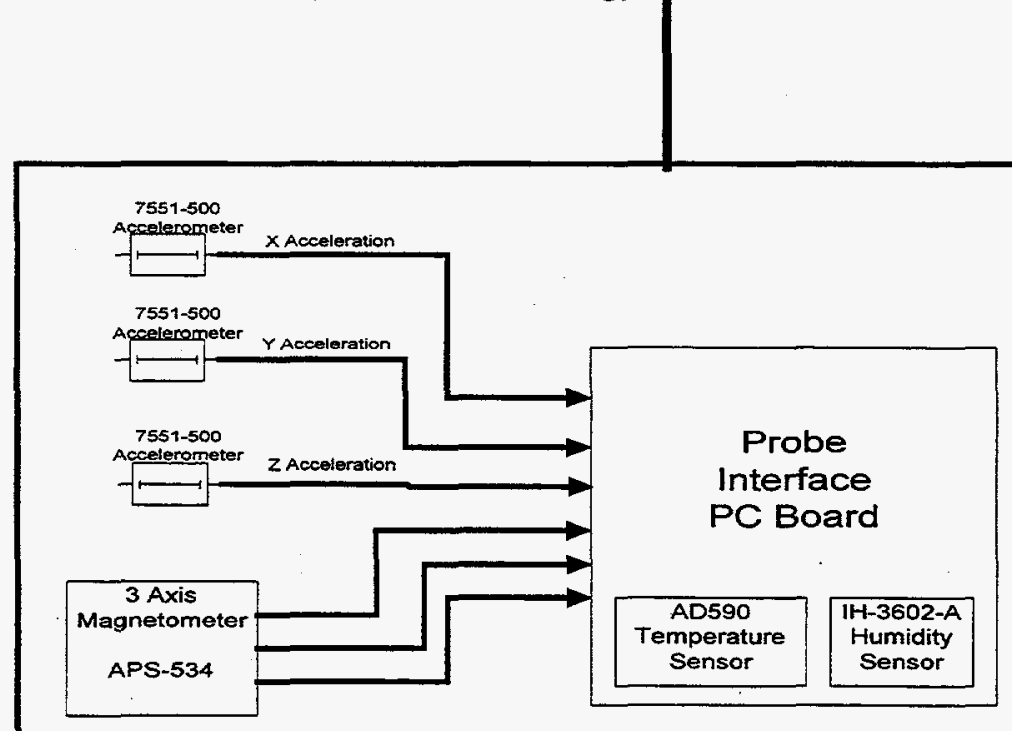

Sea Floor Seismic Probe

Figure III: SEMS IV Instrumentation System 


\section{Measurement Specifications}

\section{II.1 Data Acquisition and Electrical Specifications}

The measurement specifications for the SEMS IV instrumentation system are provided in

Table III. Detailed discussion of the electronics design and calibration are provided in Section III. Electrical Interface Specifications are provided in Table IV.

Table III: SEMS IV Measurement Specifications

\begin{tabular}{|c|c|}
\hline \multicolumn{2}{|c|}{ Transolucer Specifications: } \\
\hline Accelerometer: & Endevco \#7551-500 \\
\hline Sensitivity: & $500 \mathrm{mv} / \mathrm{g}$ (nominal) \\
\hline Residual Noise: & $25 \mu \mathrm{Vrms}$ \\
\hline Magnetometer: & Applied Physics Systems: APS-534 \\
\hline Sensitivity: & $4.0 \mathrm{~V} / \mathrm{Gauss}$ \\
\hline Axis Alignment: & $\pm 2.0^{\circ}$ (to true orthogonal) \\
\hline $\begin{array}{l}\text { Humidity Sensor: } \\
\text { Accuracy: }\end{array}$ & $\begin{array}{l}\text { Hy-Cal Engineering, IH-3602-A } \\
\pm 2.0 \% \mathrm{RH}\end{array}$ \\
\hline $\begin{array}{l}\text { Temperature Sensor: } \\
\text { Accuracy: }\end{array}$ & $\begin{array}{l}\text { Analog Devices, } \mathrm{AD} 590 \\
\pm 2.0^{\circ} \mathrm{C}\end{array}$ \\
\hline Water Detection & 1 Water Contact Switch \\
\hline \multicolumn{2}{|c|}{ Recorder Spectifcutions (0680/LT-G): } \\
\hline High Resolution Channels: & 6 \\
\hline Sampling Rate: & 80 sample/sec (per channel) \\
\hline Bandwidth: & 0 to $32 \mathrm{~Hz}$ \\
\hline Resolution: & 24 bits \\
\hline Dynamic Range: & $148 \mathrm{~dB}$ \\
\hline Input Range: & \pm 20 Volts \\
\hline Noise Floor (Input Shorted): & -145 dB (re: Full Scale Input) \\
\hline Monitor Channels: & 6 \\
\hline Sampling Interval: & 100 seconds per sample (per channel) \\
\hline Resolution: & 8 bits \\
\hline Input Range: & \pm 12.5 Volts \\
\hline \multicolumn{2}{|c|}{ Signol Conditioner Specfications(OPREAMMP): } \\
\hline Number of Channels & 3 \\
\hline Current Source & 2 ma (constant current). \\
\hline Bandwidth (3 dB) & 0.5 to $500 \mathrm{~Hz}$ \\
\hline Gain & $10.0( \pm 4 \%)$ \\
\hline Input Equivalent Noise & $50 \mathrm{nV} / \sqrt{\mathrm{Hz}}(100 \Omega, 5$ to $200 \mathrm{~Hz})$ \\
\hline
\end{tabular}


Table IV: SEMS IV Electrical Interface Specifications

\begin{tabular}{|l|l|}
\hline Data Interface: \\
\hline Data Acquisition Software: & Quanterra Shear, R-34/02-RL1231S \\
\hline Dial Up Modem Software: & Quanterra, PCSeed, Rev. 3/8/94 \\
\hline Modem & Telebit World Blazer \\
\hline Time Code & GPS C/A code \\
\hline Timing Accuracy & $1 \mu$ sec to UTC \\
\hline \multicolumn{2}{|l}{} \\
\hline Poower Requirements: & $24 \mathrm{~V}$ to 28V \\
\hline Operating Voltage: & $1.8 \mathrm{~A}$ (entire system) \\
\hline Operating Current: & Eagle Picher \#5H-10 \\
\hline Back Up Battery: & 5.0 A-hours \\
\hline Back Up Battery Capacity: & 2.8 hours \\
\hline Back Up Battery Operating Life: &
\end{tabular}

\section{II.2 Mechanical Specifications}

The outer diameter of the probe assembly is 5.65 inches and the weight is 24.83 pounds. The probe's specific gravity was designed to closely match that of the known specific gravity of the seafloor around the three platforms. The following specific gravity values were obtained from MMS; Grace, 2.02 at the twenty foot depth, Eureka, 1.76 at the twenty to twenty-five foot depth and at Irene, 1.96 at the ten to twenty foot depth. The designed specific gravity of the probe was 1.93 . The closer the specific gravity match-up the better the mechanical coupling, thus the better the data.

\section{II.3 Environmental Specifications}

The probe must be capable of withstanding the pressures associated with water depths of up to eight hundred feet ( $\sim 400$ psi.) The probe must also withstand the intense vibration caused by the vibrocorer. The O-ring seals, as well as the internal electronics, must survive these harsh environments. The probe design consists of an inner sealed electronics module and an outer sealed structural shell. The combination of these two, gives us a redundant sealing system for potential water leakage caused by the severe pressure and vibration environments. Once installed, the probe should be capable of surviving in the seafloor for many years of leak proof operation.

\section{Instrumentation Design and Calibration}

\section{III.1 Instrumentation Design Overview}

\section{III.1.1 Probe Electronics Description}

The design of the SEMS IV instrumentation system was based on the premise of minimizing circuitry in the probe and the use of commercially supplied equipment topside at the platforms. A small circuit board is mounted in the seafloor probe assembly. This circuit board provides for installation of the humidity and temperature sensors and signal conditioning amplifiers for the magnetometer signals. This circuit board also serves a wiring termination point for the underwater cable, which connects the probe to the recorder circuitry on the platforms. Note that there is no signal conditioning for the accelerometer signals in the probe. The accelerometers are terminated directly to the coaxial cable elements inside the underwater cable, which connect them directly to the 
Quanterra constant current amplifier units (see Figure III.) The schematic for the probe electronics board is included in Appendix A.

\section{III.1.2 Control Panel Description}

The upper termination of the underwater probe cable is the SEMS IV control panel installed topside at each platform. The control panel serves as a wiring panel from the probe cable to the seismograph inputs. This panel also houses the modem. The control panel also provides AC/DC power conversion for the system and a patch panel of all probe outputs for convenience in electrical monitoring in maintenance or trouble shooting situations. A circuit board mounted in the control panel provides amplification and signal conditioning needed for the magnetometer, probe temperature and humidity sensor outputs. These signals are converted to single-ended outputs which can be directly recorded in the Quanterra. Control panel wiring and schematics are provided in Appendix A.

\section{III.1.3 Seismograph Description}

The SEMS IV development afforded the opportunity to survey the market for a seismograph with high performance and operational flexibility. We investigated about six suppliers and performed a detailed comparison of the top three. The Quanterra, QL680/LT-G was clearly superior to the other units. It is a microprocessor based seismic event detector and recorder. The operating system is UNIX and supports a powerful software package designed for seismic event detection and data storage. The software also supports modem operation allowing the event and housekeeping data to be accessed via phone lines. Modems were installed at each of the platforms and Sandia personnel have been regularly monitoring the state of health of the probes and downloading event data over the phone lines from Albuquerque. The Quanterra seismograph also includes a GPS interface for time correlation. Unfortunately, we were unable to install the GPS antennas on the platforms. The antennas, cables and miscellaneous hardware, are located at each of the platforms, ready for installation. Detailed information about the seismograph software and operation is available from Quanterra. For detailed information, Quanterra can be contacted directly:

Quanterra, Inc.

325 Ayer Rd.

Harvard, MA 01451

Phone: 508.772.4774

Fax: 508.772.4645

\section{III.1.4 Underwater Probe Connector and Cable Assembly}

One of the key design elements of any tethered cable instrumentation system is the underwater cable which connects the probe to the seismograph mounted on the platforms. SEMS IV used SeaCon cables and connectors for all underwater connections. SeaCon components had been used in previous SEMS applications and SeaCon has demonstrated high quality products. The SEMS IV cables include three coax elements along with fourteen individual conductors at AWG \#20. Sandia ordered the underwater cable and connector assembly as a custom delivery from SeaCon. The cable was constructed with a Kevlar jacket around the conductors for improved pull strength. Specifications for the underwater cable and connector assembly as used for SEMS IV are provided in Table V. 
Table V: SEMS IV Underwater Cable Specifications

\begin{tabular}{|l|l|}
\hline \multicolumn{2}{|l|}{ Connector Specifications: } \\
\hline Connector Model \# & MINL-20-CCP \\
\hline Pin Count: & 6 @ 20 AWG \\
& $14 @ 22$ AWG \\
\hline Cable Electrical Specifications: & \multicolumn{2}{|l|}{} \\
\hline Coax Elements: & 3 @ RG-316 \\
& Shields Isolated \\
\hline Individual Conductors: & 14 \\
Size: & AWG \#22 \\
Resistance: & $18 \Omega / 1000 \mathrm{ft}$ \\
Voltage Rating: & 600 Volts \\
\hline Cable Mechanical Specifications: & \\
\hline Nominal OD: & $0.49^{\prime \prime}$ \\
\hline Weight in Air: & $143 \mathrm{lb} . / 1000 \mathrm{ft}$. \\
\hline Weight in Sea Water: & $60 \mathrm{lb} / 1000 \mathrm{ft}$. \\
\hline Breaking Strength: & $5000 \mathrm{lb}$. \\
\hline Maximum Load: & $700 \mathrm{lb}$. \\
\hline Min. Bend Diameter: & $20^{\prime \prime}($ loaded) \\
\hline
\end{tabular}

\section{III.2 Instrument Calibration}

The SEMS IV transducers and electronics signal conditioning were all fully tested and calibrated prior to installation at the platforms. Calibration for the transducers and electronics in each of the three systems are provided in Table VI, Table VII, Table VIII. In considering the information in Table VI, Table VII, Table VIII, note that the "Gauge Sensitivity" listed represents the raw gauge sensitivity before applying any gain to the signals. Since there is no gain applied to any of the signals in the probe, this sensitivity also represents the signal levels as measured at the "Probe" monitor points on the control panel at the platforms. Note that all of the signals, except accelerometers, are amplified in the control panel (see Signal Gain in Table VI, Table VII), and the amplified signal levels are routed to the seismograph recorder inputs. These amplified signals can also be measured on the control panel at the "Panel" monitor points. The "Input Range" column is the full scale signal range at the seismograph inputs. The "Data Sensitivity" information can be used to convert seismograph readings in counts to engineering units. Note that the Data Sensitivity entries for the magnetometer measurements are listed in $\mu \mathrm{V} / \mathrm{cnt}$ rather than the engineering units of $\mu$ Gauss/cnt. The reason for this, is that the magnetometer data must be normalized to the local magnetic field strength of the earth at the installation location to produce a useful interpretation. The application of the magnetometer data to measure orientation is discussed in Section III.3 and is based on normalized magnetometer readings in units of volts.

In order to calculate probe temperature or relative humidity, a simple linear equation calculation is used based on the sensitivity information from Table VI, Table VII, Table VIII. Note that the calibration constants for the temperature and relative humidity sensors are identical in Table VI, Table VII, Table VIII. This is because nominal calibration readings of one of the systems is used for all three stations. These readings are meant only as diagnostic indicators and were not calibrated individually for each station. Calculation of the probe temperature or relative humidity from 
seismograph readings in counts can be made using Equations III.1 (temperature) and III.2 (relative humidity).

Probe Temperature $=30^{\circ} \mathrm{F}+(\text { Tcounts }-93)^{*}(0.857)^{\circ} \mathrm{F}$ (Equation III.1)

Probe Relative Humidity $=(\mathrm{RH}$ counts -144$) *(1.503) \% \mathrm{RH}$ (Equation III.2)

Table VI: Calibration for SEMS IV Probe at Eureka

\begin{tabular}{|c|c|c|c|c|c|c|c|}
\hline $\begin{array}{l}\text { Signal } \\
\text { Name }\end{array}$ & $\begin{array}{c}\text { Gauge } \\
\text { Model \# }\end{array}$ & $\begin{array}{l}\text { Gauge } \\
\text { Serial \# }\end{array}$ & $\begin{array}{c}\text { Gauge } \\
\text { Sensitivity }\end{array}$ & $\begin{array}{l}\text { Signal } \\
\text { Gain }\end{array}$ & $\begin{array}{l}\text { Input } \\
\text { Range }\end{array}$ & $\begin{array}{c}\text { Data } \\
\text { Sensitivity }\end{array}$ & $\begin{array}{l}\text { Sampling } \\
\text { Rate }(\mathrm{Hz})\end{array}$ \\
\hline $\begin{array}{c}\text { X-Axis } \\
\text { Accelerometer }\end{array}$ & $7751-500$ & AF7M2 & $\begin{array}{l}0.494 \\
(\mathrm{~V} / \mathrm{g})\end{array}$ & 10.37 & $\pm 20 \mathrm{~V}$ & $\begin{array}{c}0.4654 \\
(\mu \mathrm{g} / \mathrm{cnt})\end{array}$ & 80 \\
\hline $\begin{array}{c}\text { Y-Axis } \\
\text { Accelerometer }\end{array}$ & $7751-500$ & AH800 & $\begin{array}{l}0.500 \\
(\mathrm{~V} / \mathrm{g})\end{array}$ & 10.29 & $\pm 20 \mathrm{~V}$ & $\begin{array}{c}0.4634 \\
(\mu \mathrm{g} / \mathrm{cnt})\end{array}$ & 80 \\
\hline $\begin{array}{c}\text { Z-Axis } \\
\text { Accelerometer }\end{array}$ & $7751-500$ & AHH29 & $\begin{array}{l}0.499 \\
(\mathrm{~V} / \mathrm{g})\end{array}$ & 10.31 & $\pm 20 \mathrm{~V}$ & $\begin{array}{c}0.4634 \\
(\mu \mathrm{g} / \mathrm{cnt})\end{array}$ & 80 \\
\hline $\begin{array}{c}\mathrm{X} \text {-Axis } \\
\text { Magnetometer }\end{array}$ & APS-534 & 558 & $\begin{array}{c}4.0 \\
\text { (V/Gauss) }\end{array}$ & 5.0 & $\pm 20 \mathrm{~V}$ & $\begin{array}{c}1.192 \\
(\mu \mathrm{V} / \mathrm{cnt})\end{array}$ & 80 \\
\hline $\begin{array}{c}\text { Y-Axis } \\
\text { Magnetometer }\end{array}$ & APS-534 & 558 & $\begin{array}{c}4.0 \\
\text { (V/Gauss) }\end{array}$ & 5.0 & $\pm 20 \mathrm{~V}$ & $\begin{array}{c}-1.192 \\
(\mu \mathrm{V} / \text { cnt })\end{array}$ & 80 \\
\hline $\begin{array}{c}\text { Z-Axis } \\
\text { Magnetometer }\end{array}$ & APS-534 & 558 & $\begin{array}{c}4.0 \\
\text { (V/Gauss) }\end{array}$ & 5.0 & $\pm 20 \mathrm{~V}$ & $\begin{array}{c}1.192 \\
(\mu V / \text { cnt })\end{array}$ & 80 \\
\hline $\begin{array}{c}\text { Probe } \\
\text { Temperature }\end{array}$ & AD590 & na & $\begin{array}{c}19.26 \\
\left(\mathrm{mV} /{ }^{\circ} \mathrm{F}\right)\end{array}$ & 6.0 & $\pm 12.5 \mathrm{~V}$ & $\begin{array}{c}0.857 \\
\left({ }^{\circ} \mathrm{F} / \mathrm{cnt}\right)\end{array}$ & 0.01 \\
\hline $\begin{array}{c}\text { Probe } \\
\text { Humidity }\end{array}$ & IH-3602-A & na & $\begin{array}{c}32.48 \\
(\mathrm{mV} / \% \mathrm{RH})\end{array}$ & 2.0 & $\pm 12.5 \mathrm{~V}$ & $\begin{array}{c}1.503 \\
(\% \mathrm{RH} / \mathrm{cnt})\end{array}$ & 0.01 \\
\hline \multicolumn{8}{|c|}{ Seismograph: QL680/TL-G: Ser. \#940902 } \\
\hline \multicolumn{8}{|c|}{ Signal Conditioner: QPREAMP: Ser. \#102331 } \\
\hline \multicolumn{8}{|c|}{ Probe: SN-01 } \\
\hline
\end{tabular}




\section{III.3 Probe Position Sensing from Magnetometer Signals}

The SEMS IV probes have a three-axis magnetometer installed for determining the position of the probes after they have been embedded in the seafloor. The nature of the vibrocorer installation technique doesn't allow any control over the rotation of the probe during the embedding process. Also, there is the potential for some tilt in the probe relative to the gravity axis. For these reasons, magnetometer signals were employed to determine the heading and tilt of the probe after they were embedded in the seafloor. Recall that the heading and tilt angles of the three probes are listed in Table I. These angles were calculated using magnetometer readings taken after the installation process was complete. The calculations are based on magnetometer calibration and normalization procedures discussed in the following sections.

\section{III.3.1 Magnetometer Calibration Measurements}

The SEMS IV magnetometer data is used to calculate the probe's orientation after being embedded in the seafloor. These orientation angles are determined by trigonometric computations based on normalized magnetometer readings. The magnetometer normalization constants were determined using DC readings of peak positive and negative voltage for each magnetometer axis. This eliminates the concern of variations in sensitivity or bias variations in the probe's magnetometer readings. Two groups of voltage readings were recorded for each of the three probes. The first set of readings is a horizontal calibration, which allows the calculation of heading angle. The horizontal calibration is done by holding the probe $\mathrm{X}$-axis perpendicular to horizontal using a bubble level. Readings are then taken with the " $+Z$ " axis of the probe pointing due North, South, East and West. These measurements were used to generate the horizontal normalization and bias terms provided in Table IX.

The second set of readings are peak readings recorded with each of the magnetometer sensing axes aligned with the peak magnetic field axis. These readings are made by aligning each magnetometer sensing axis with the dip angle of the peak magnetic field lines of the earth to record a peak magnetic field reading in each axis. These measurements were used to generate the "Peak" normalization constants provided in Table X. Since the dip angle and magnetic "North" vary with global position and proximity to metal buildings or structures, the "Horizontal" and "Peak" magnetometer calibration measurements were made on Seal Beach in Southern California on the day before installation began.

The dip angle in the earth's magnetic field varies with position relative to the equator (latitude). The magnetometer calibration exercises included a calculation of the dip angle at Seal Beach. These measurements agreed well betueen the probes and the dip angle was determined to be $32.5^{\circ}$. 
Table IX: Horizontal Axis Magnetometer Calibration for SEMS IV Probes

\begin{tabular}{|c|c|c|c|c|}
\hline $\begin{array}{l}\text { Signal } \\
\text { Name }\end{array}$ & $\begin{array}{c}\text { Positive } \\
\text { Maximum (V) }\end{array}$ & $\begin{array}{c}\text { Negative } \\
\text { Maximum (V) }\end{array}$ & $\begin{array}{l}\text { Horizontal Normalizing } \\
\text { Factor }(\mathrm{V})\end{array}$ & $\begin{array}{l}\text { Horizontal } \\
\text { Bias (V) }\end{array}$ \\
\hline $\begin{array}{l}\text { Y-Axis, Eureka } \\
\text { (Probe SN-01) }\end{array}$ & $\begin{array}{c}3.016 \\
(+Z \text { East })\end{array}$ & $\begin{array}{c}-2.183 \\
(+Z \text { West })\end{array}$ & 2.599 & 0.4165 \\
\hline $\begin{array}{l}\text { Z-Axis, Eureka } \\
\text { (ProbeSN-01) }\end{array}$ & $\begin{array}{c}2.822 \\
(+Z \text { South })\end{array}$ & $\begin{array}{c}-2.660 \\
(+Z \text { North })\end{array}$ & 2.741 & 0.081 \\
\hline $\begin{array}{l}\text { Y-Axis, Grace } \\
\text { (Probe SN-03) }\end{array}$ & $\begin{array}{c}3.074 \\
\text { (+Z East) }\end{array}$ & $\begin{array}{c}-1.878 \\
(+Z \text { West })\end{array}$ & 2.476 & 0.598 \\
\hline $\begin{array}{l}\text { Z-Axis, Grace } \\
\text { (Probe SN-03) }\end{array}$ & $\begin{array}{c}5.117 \\
\text { (+Z South) }\end{array}$ & $\begin{array}{c}-0.126 \\
(+Z \text { North })\end{array}$ & 2.621 & 2.495 \\
\hline $\begin{array}{l}\text { Y-Axis, Irene } \\
\text { (Probe SN-02) }\end{array}$ & $\begin{array}{c}2.566 \\
(+Z \text { East })\end{array}$ & $\begin{array}{c}-2.734 \\
(+Z \text { West })\end{array}$ & 2.650 & -0.084 \\
\hline $\begin{array}{l}\text { Z-Axis, Irene } \\
\text { (Probe SN-02) }\end{array}$ & $\begin{array}{c}4.770 \\
\text { (+Z South) }\end{array}$ & $\begin{array}{c}-0.871 \\
(+Z \text { North })\end{array}$ & 2.820 & 1.949 \\
\hline \multicolumn{5}{|c|}{ Eureka (Probe SN-01), X-Axis $=-4.230 \mathrm{~V}$} \\
\hline \multicolumn{5}{|c|}{ Grace (Probe SN-03), X-Axis $=-4.480 \mathrm{~V}$} \\
\hline \multicolumn{5}{|c|}{ Irene (Probe SN-02), X-Axis $=-3.785 \mathrm{~V}$} \\
\hline
\end{tabular}

Table X: Peak Axis Magnetometer Calibration for SEMS IV Probe

\begin{tabular}{|c|c|c|c|c|}
\hline $\begin{array}{c}\text { Signal } \\
\text { Name }\end{array}$ & $\begin{array}{c}\text { Positive } \\
\text { Peak (V) }\end{array}$ & $\begin{array}{c}\text { Negative } \\
\text { Peak (V) }\end{array}$ & $\begin{array}{c}\text { Peak } \\
\text { Normalizing } \\
\text { Factor (V) }\end{array}$ & $\begin{array}{c}\text { Peak } \\
\text { Bias (V) }\end{array}$ \\
\hline $\begin{array}{c}\text { X-Axis, Eureka } \\
\text { (Probe SN-01) }\end{array}$ & 4.820 & -5.000 & 4.910 & -0.090 \\
\hline $\begin{array}{c}\text { Y-Axis, Eureka } \\
\text { (Probe SN-01) }\end{array}$ & 5.167 & -4.992 & 5.079 & 0.157 \\
\hline $\begin{array}{c}\text { Z-Axis, Eureka } \\
\text { (Probe SN-01) }\end{array}$ & 4.360 & -5.200 & 4.780 & -0.420 \\
\hline $\begin{array}{c}\text { X-Axis, Grace } \\
\text { (Probe SN-03) }\end{array}$ & 5.320 & -5.130 & 5.225 & 0.095 \\
\hline $\begin{array}{c}\text { Y-Axis, Grace } \\
\text { (Probe SN-03) }\end{array}$ & 4.467 & -5.700 & 5.083 & -0.616 \\
\hline $\begin{array}{l}\text { Z-Axis, Grace } \\
\text { (Probe SN-03) }\end{array}$ & 7.900 & -2.910 & 5.405 & 2.495 \\
\hline $\begin{array}{c}\text { X-Axis, Irene } \\
\text { (Probe SN-02) }\end{array}$ & 5.260 & -4.570 & 4.915 & 0.345 \\
\hline $\begin{array}{c}\text { Y-Axis, Irene } \\
\text { (Probe SN-02) }\end{array}$ & 4.930 & -4.760 & 4.845 & 0.085 \\
\hline $\begin{array}{c}\text { Z-Axis, Irene } \\
\text { (Probe SN-02) }\end{array}$ & 7.126 & -3.144 & 5.135 & 1.991 \\
\hline
\end{tabular}




\section{III.3.2 SEMS IV Probe Orientation Measurements and Calculations}

The orientation angles of the SEMS IV probes are determined from calculations based on the calibration results from the previous section and magnetometer readings taken after the probes were embedded in the seafloor. The heading angles are calculated from the normalized $Y$ and $Z$ axis magnetometer readings as follows.

$$
\begin{array}{ll}
\text { Ysig }=(\text { Ymag }- \text { Ybias }) / \text { Ynorm } & \text { Equation III.3 } \\
\text { Zsig }=(\text { Zmag }- \text { Zbias }) / Z \text { Znorm } & \text { Equation III.4 } \\
\text { Heading }=\text { ArcTan }(Y s i g / Z s i g) & \text { Equation III.5 }
\end{array}
$$

Note that the quadrant of the heading angle is determined from the numerical sign of Ysig and Zsig. So, negative Zsig implies North, positive Zsig implies South, and negative Ysig implies West.

Table XI includes the results of the heading and tilt angles for all three platforms. The "Heading Angles" refer to the position of the " $+Z$ " sensing axis of the probe relative to magnetic North. All of the magnetometer readings and calculations were reviewed at this writing. A few minor calculation errors were made in the initial calculations which were reported in the memo released immediately following the SEMS IV installation (memo dated July 24, 1995). Any remaining copies of that memo should be eliminated and the data from Table XI used in its place.

Table XI: SEMS IV Probe Orientation Angles

\begin{tabular}{|c|c|c|c|}
\hline $\begin{array}{c}\text { Signal } \\
\text { Name }\end{array}$ & $\begin{array}{c}\text { Eureka } \\
\text { Probe (SN-01) }\end{array}$ & $\begin{array}{c}\text { Grace } \\
\text { Probe (SN-03) }\end{array}$ & $\begin{array}{c}\text { Irene } \\
\text { Probe (SN-02) }\end{array}$ \\
\hline Ymag (Volts) & 1.866 & -1.638 & 0.235 \\
\hline Ysig & 0.5577 & -0.9031 & 0.1204 \\
\hline Zmag (Volts) & -1.943 & 1.309 & -0.692 \\
\hline Zsig & -0.7384 & -0.4527 & -0.9365 \\
\hline Heading Angle & $37.1^{\circ}$ & $63.4^{\circ}$ & $7.3^{\circ}$ \\
\hline Heading Quadrant & East of Due North & West of Due North & East of Due North \\
\hline Xmag (Volts) & -4.341 & -4.16 & -3.85 \\
\hline Xsig & 0.866 & 0.8144 & 0.854 \\
\hline Tilt Angle & $2.5^{\circ}$ & $2.9^{\circ}$ & $1.1^{\circ}$ \\
\hline
\end{tabular}

Note: The Heading angle describes orientation of the $+Z$ accelerometer axis to magnetic North.

One last calculation is required to define the orientation of the SEMS IV probes. The calculation of the tilt angle requires the use of the $\mathrm{X}$-axis Peak Calibration constants (Table $\mathrm{X}$ ) and the $\mathrm{X}$-axis readings after probes were embedded. The tilt angle from horizontal is calculated as follows.

$$
\begin{array}{ll}
\text { Xsig }=(X m a g-\text { Xbias }) / X n o r m & \text { Equation III.6 } \\
\text { Tilt }=\text { Dip }- \text { ArcCos }(\text { Xsig }) & \\
\text { Tilt }=32.5^{\circ}-\text { ArcCos (Xsig) } & \text { Equation III.7 }
\end{array}
$$

Table XI provides a summary of the tilt angle readings and calculations for the orientation of the three SEMS IV probes. Once again, calculation errors were made in one of the three tilt angles as reported in the original SEMS IV installation memo. 
Table XI should be used for future reference. Note that all of the tip angles are fairly small. Comparison of the $\mathrm{X}$-axis magnetometer readings from the horizontal position before embedding (Table IX) with the final readings (after embedding) suggests that the tilt angles are, in fact, small.

\section{Mechanical Design}

The mechanical design was benefited by the fact that a previous design was available for review and examination. We were able to discover valuable information from the previous design, which proved instrumental to the success of our design. Pro/Engineer CAD software was utilized in the development of this probe.

\section{IV.1 Previous Probe Design}

Upon review of the earlier probes, we noticed five areas of concern.:

1.) The connector that exits the probe was positioned in such a way that it was susceptible to damage from the removal of the coretube during the installation procedure. It was very possible that during the removal of the coretube, after the coretube wire rope was cut, the coretube could smash into the connector causing electrical failure or a break in the seal integrity of the connector.

2.) Poorly sealed aft section of the probe. It appeared to us that potting material was used as the main sealing method for the exiting cable. It is not normally recommended to seal with a hard potting material at these pressures and severe vibration environments. It is hard to guarantee that potting material will completely seal around wires in cable.

3.) The two-axis magnetometer made alignment measurement difficult.

4.) Possible O-ring seal design problems. There were no redundant O-rings joints in the earlier designs of the probe..

5.) Electrical assembly had to be potted to obtain structural integrity.

\section{IV.2 Lessons Learned; Previous Probe and Previous Installation Process}

The installation of these probes is a difficult task to say the least. There is an assortment of things that could go wrong, thus jeopardizing the chance for a successful installation. We tried to analyze the previous installation procedures to better understand them and to hopefully correct any problems we saw.

1.) Bad weather is a major concern for the installation. Once the installation cage is set on the seafloor, and the probe is ready for the vibrocorer, if a large swell hits the boat at the wrong time, it can cause a serious problem for the probe. The probe could be violently pulled out of its installation hole, causing seal damage or electrical cable damage. We suspect this to be the cause of a previous probe failure. 
2.) Bad coring information. If the seafloor is to hard or it happens to be sitting on rocks, the vibrocorer will not be able to penetrate the surface. The probe will be subjected to excessive vibration, causing seal or internal damage to the sensitive electronics.

3.) Excess cable lying on the seafloor. If there is too much extraneous cabling on the seafloor, fishing boat anchors are prone to snag the electrical cable running to the platform and pull it out, thus terminating the probe. Also, the cable was not weighted down and was free to move.

4.) Cumbersome installation of the probe to the vibrocorer/coretube. There is a potential for damage caused by the remotely operated underwater vehicle (ROV) while cutting the Kevlar strapping that secures the probe to the coretube. Swells and currents could cause the ROV to accidentally hit the coretube and cause electrical failure.

\section{IV.3 Current Probe Design}

The current SEMS IV design took advantage of previous designs, allowing us to maximize our design potential. The probe was designed and engineered to maximize the survivability of the electronics under adverse deep water conditions and to minimize damage during the violent installation process. See Appendix $\mathrm{C}$ for a complete catalog of the mechanical drawings used in the fabrication of the probe hardware. Refer to Figure IV for a 3-D cutout representation of the probe and all it components.

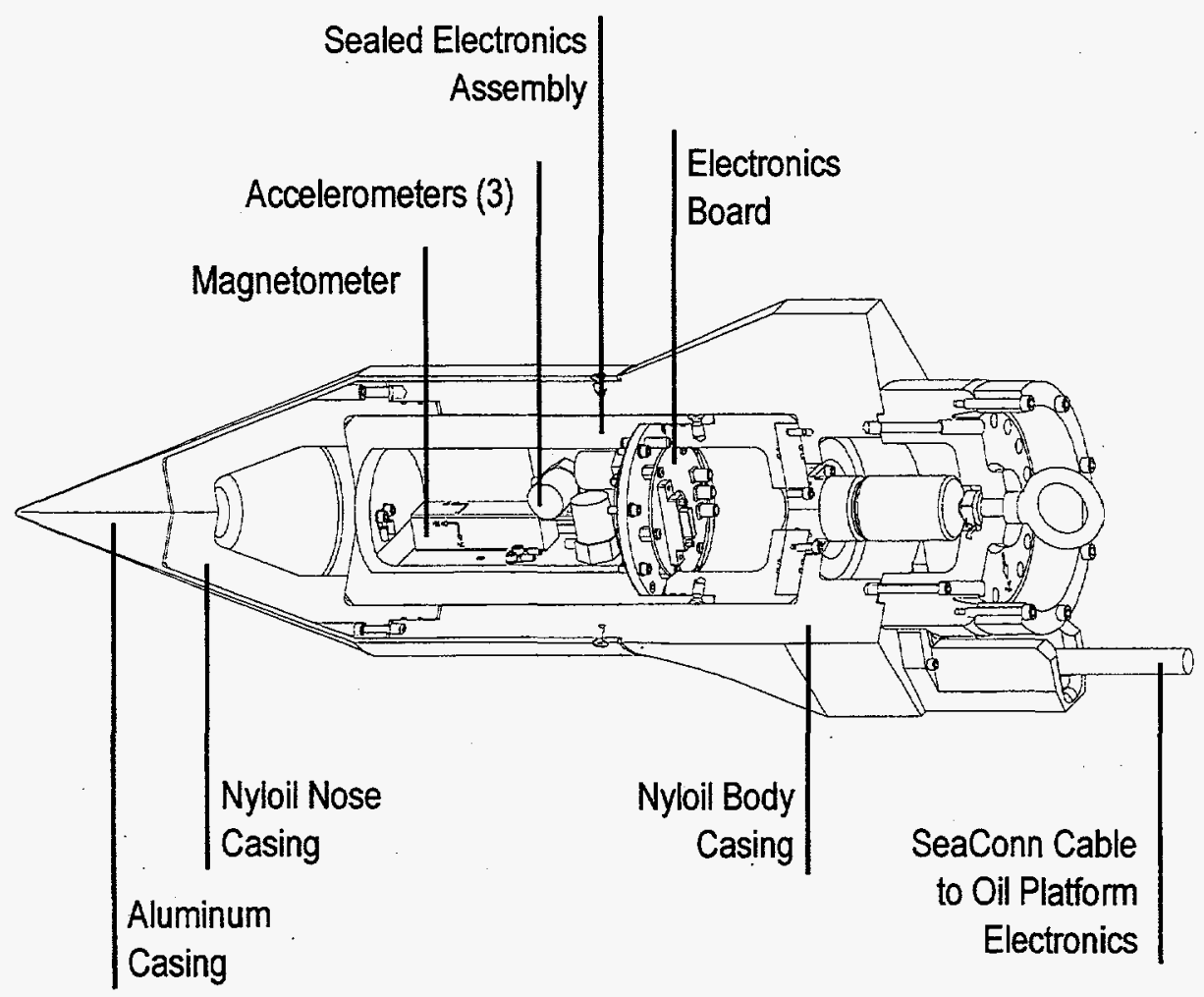

Figure IV: Cutout view of SEMS IV Probe

The probe design consists of two individually sealed modules. The inner sealed module is made out of thick-walled machined aluminum, 6061-T6, with a black anodized protective coating. Electronics boards and components are secured within this module on a nylon support structure. Positioned 
within in this module are the three Endevco 7751-500 accelerometers, Applied Physics three-axis Magnetometer, humidity sensor, temperature sensor and the water leak detection system. This module is sealed with a double set of O-rings (Nitrile, 70 Durometer). Exiting the back end of this assembly is the underwater sealed connector from SeaCon. This attaches to the data/power cable from the platform.

The outer sealed casing assembly is also designed with a double set of O-rings (Nitrile, 70 Durometer). This assembly consists of two thick walled machined Nyloil cases, secured using sixteen No. 8 high strength screws. Nyloil is a cast nylon product with very low water absorption characteristics and good mechanical properties. The main purpose of this assembly is to provide a water tight protective covering over the electronics module. Since this outer Nyloil case is where the vibrocorer and coretube attach to the probe, this assembly is also needed to be the main structural member. An aluminum protective cover screws into the back end of this assembly, protecting the underwater connector/cable and providing a groove which accepts the coretube from the vibrocorer. An eyebolt is attached to this cover, permitting an attachment point for the wire rope from the vibrocorer. After everything is assembled, another aluminum casing is attached to the forward section of the outer assembly. This sharp nosed aluminum case will aid the penetration in the seafloor.

If the outer sealed structure developed a water leak during installation, the inner module would still function, independent of the outer structure. Having the electrical/signal cable attached to this inner sealed module, we decouple the inner electronics from the outer structural assembly.

The cable running from the probe was weighted with one-half inch steel wire rope to help ballast the cable. The wire rope was attached to the cable at fifty foot intervals, ensuring the cable would settle down in the silt of the ocean floor. 


\section{Installation Procedures}

Our intent here is to outline the steps necessary for the successful installation of these probes and to document this process in the event that another set of seismic probes may be installed. Input from APM was solicited to educate the team in installation techniques, underwater rigging, and general sea operations.

With the four-point mooring in place, approximately five hundred feet from the platform, we were ready to begin the probe installation process. See Figure $V$ for a look at the boat we used during the installation of the probes.

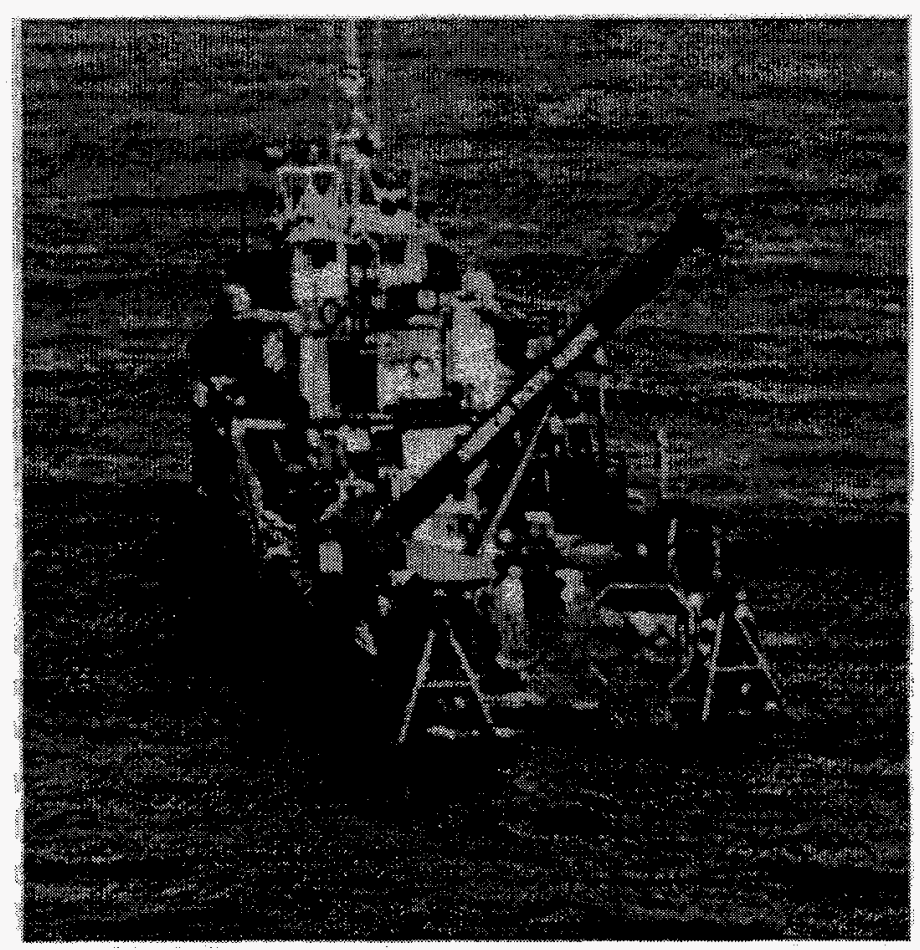

Figure V: View of APM's Boat

First, a polypropylene cable was attached to the eyebolt on the back end of probes protective cover and fished through the coretube. The coretube was then slid into the groove on the protective cover plate and the polypropylene cable is tightened with a turnbuckle to a structure located on the back end of the vibrocorer. This cable tension secured the probe to the coretube insuring vertical penetration of the probe/coretube assembly. This vibrocorer/coretube/probe assembly was slid into the installation cage and positioned vertically on the deck using the boat's crane. Refer to Figure VI and Figure VIII for a view of the cage on the deck. In these pictures you can see the installation cage with the vibrocorer and the coretube/probe attached, ready to go over the deck for installation. 


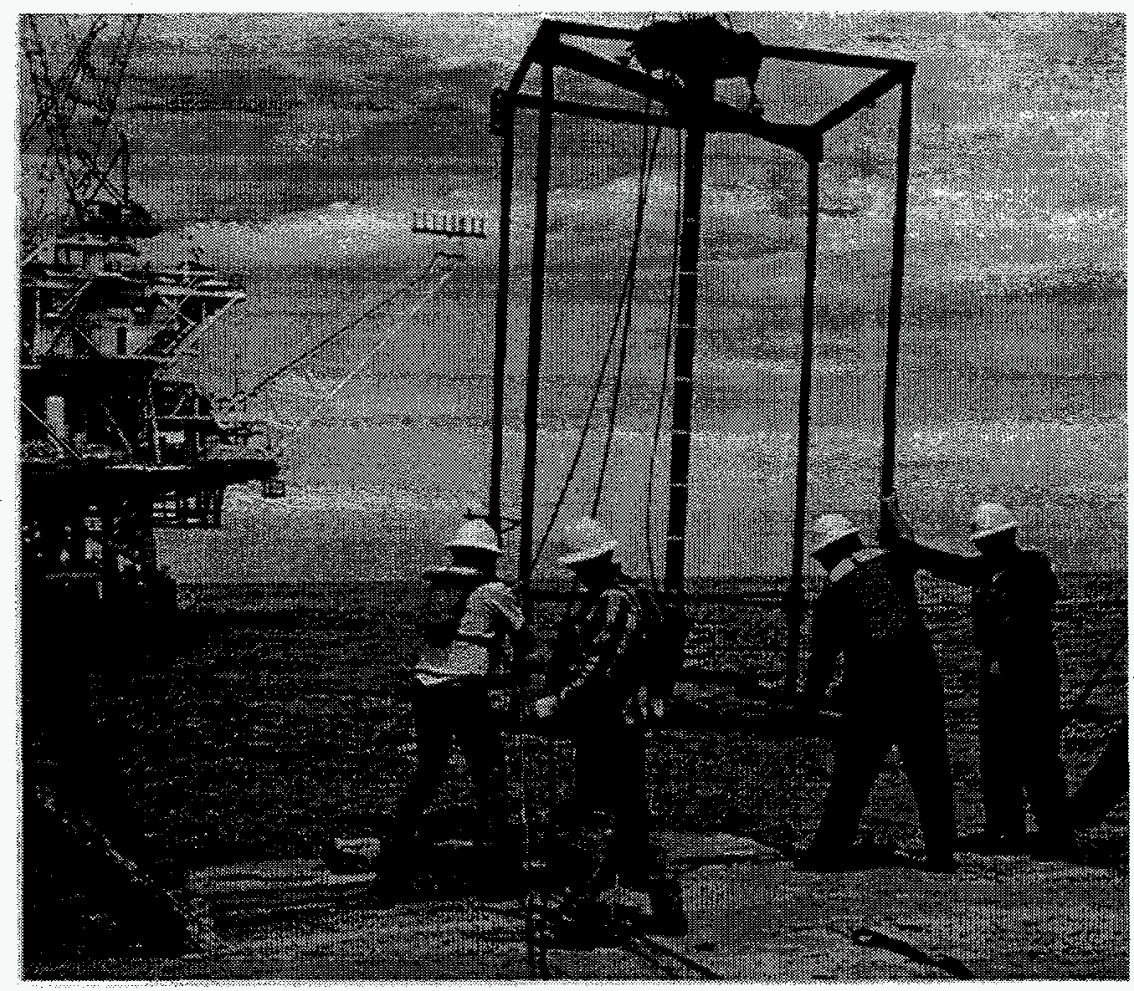

Figure VI: View of Installation Cage as it is lowered over the boat

The crane was attached to the installation cage to begin the slow descent to the ocean floor below (See Figure VI.) Meanwhile, the underwater ROV had been deployed and was waiting on the seafloor at the location where the probe would be vibrated into the ocean floor. A camera was attached to the ROV and with video feed into a control room on the boat, we were able to watch as the crane lowered the installation cage to the ocean floor. Once the cage was stable on the floor, the vibrocorer was activated and the unit began to vibrate and slowly penetrate the ocean floor. There are one foot markings painted on the coretube to determine the penetration depth of the probe. Our goal was to get around eight feet of penetration. Once the probe was sufficiently embedded, the ROV used one of its robotic arms and cut the polypropylene line, thus releasing the probe from the vibrocorer and coretube. Once free, the crane pulled the installation cage to the boat deck. Using its robotic arm, the ROV backfilled the hole left behind by the coretube. The ROV was then attached to the cable from the probe and slowly laid it along the ocean floor as the ROV traveled the 500 feet to the oil platform. Once it located the riser or J-tube, it attached the cable to a feeder line already in place. J-tubes are existing piping structures that go from the ocean floor to different locations within the platform. They are designed for routing of cables, etc. Access to the platforms allowed us to use the existing J-tubes and risers for our instrumentation cables. The topside crew then pulled the cable up to the platform's first deck junction box. The cable from the junction box to the control room had previously been routed and was waiting for our deployment. Once we attached the ocean cable to the cable located inside the junction box, we were ready to begin the installation of the electronics and data acquisition system topside. This will be discussed in detail later in the report. 
In Figure VII, you see the vibrocorer and coretube assembly. Lying behind it, is the underwater cable that gets laid out along the seafloor to the platform J-tubes and risers.

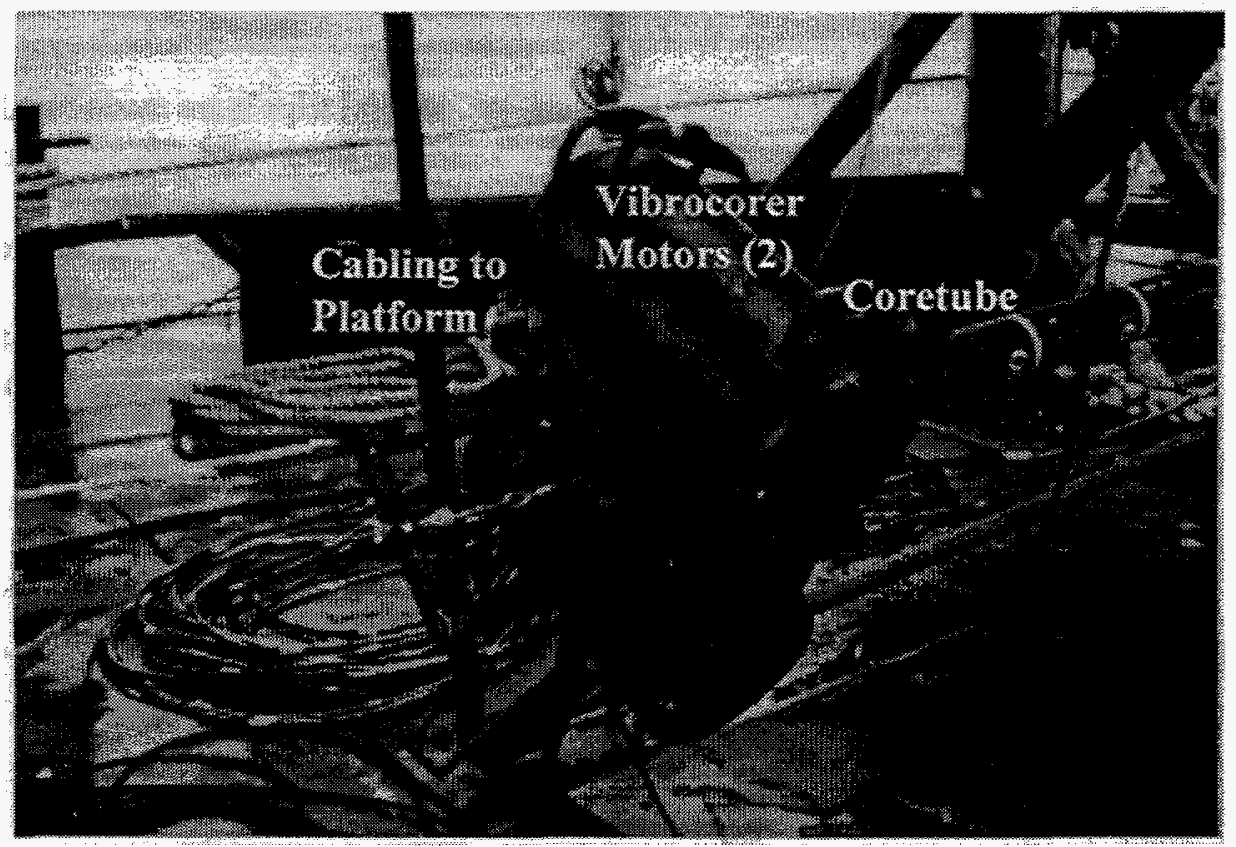

Figure VII: Vibrocorer and coretube hardware

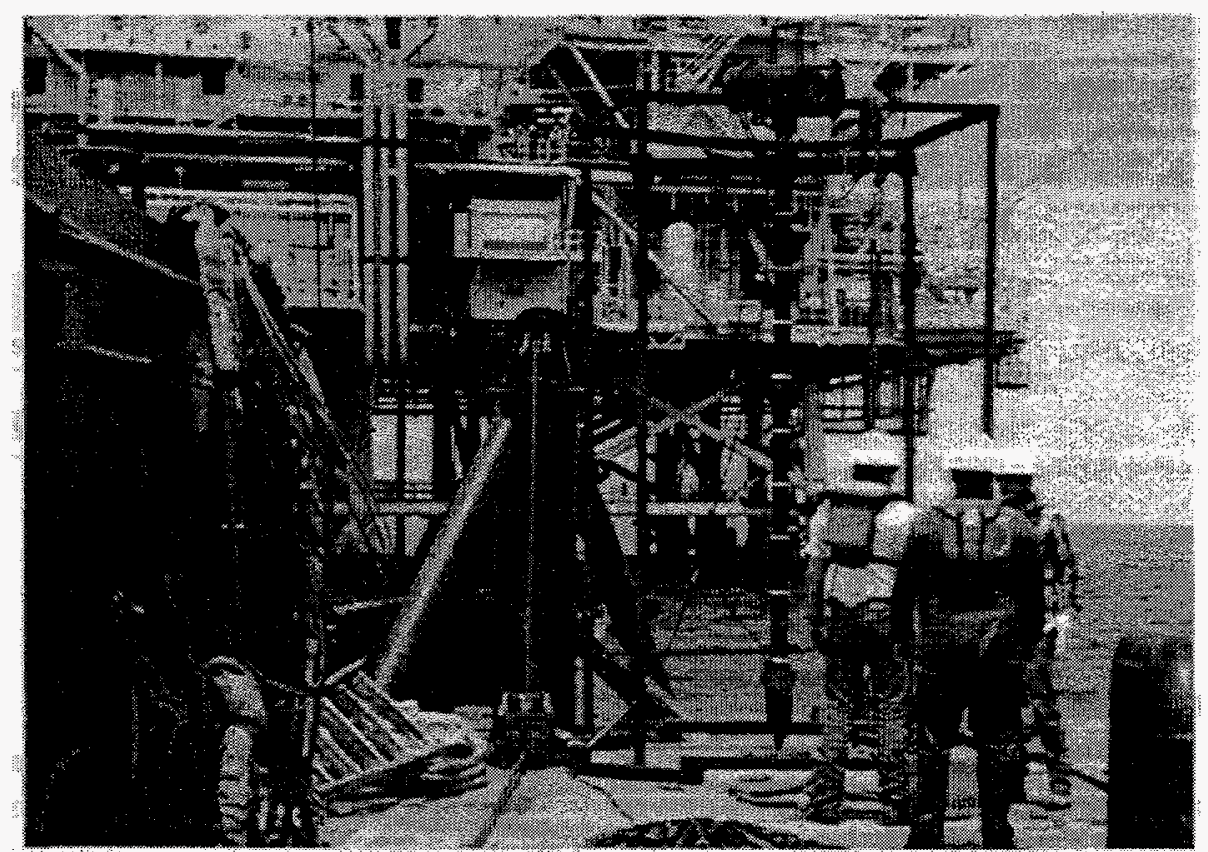

Figure VIII: View from back of boat looking towards oil platform 


\section{Installation}

The installation took place July 9-14, 1995. Prior to this date, several trips were made to APM and MMS reviewing and planning for the upcoming installation. During these trips, we hand carried the probes, Quanterra recorders, and numerous other electronics equipment to be used for the installation. MMS then setup the delivery of the electronics equipment needed for the topside platform installation. Prior to this date, APM coordinated the topside wiring and prep work needed for the routing of the probe wires to the control rooms. All this early prep work allowed us to concentrate on the installation of the probes. Refer to Figure IX for general locations of probes in relation to the California coast line.

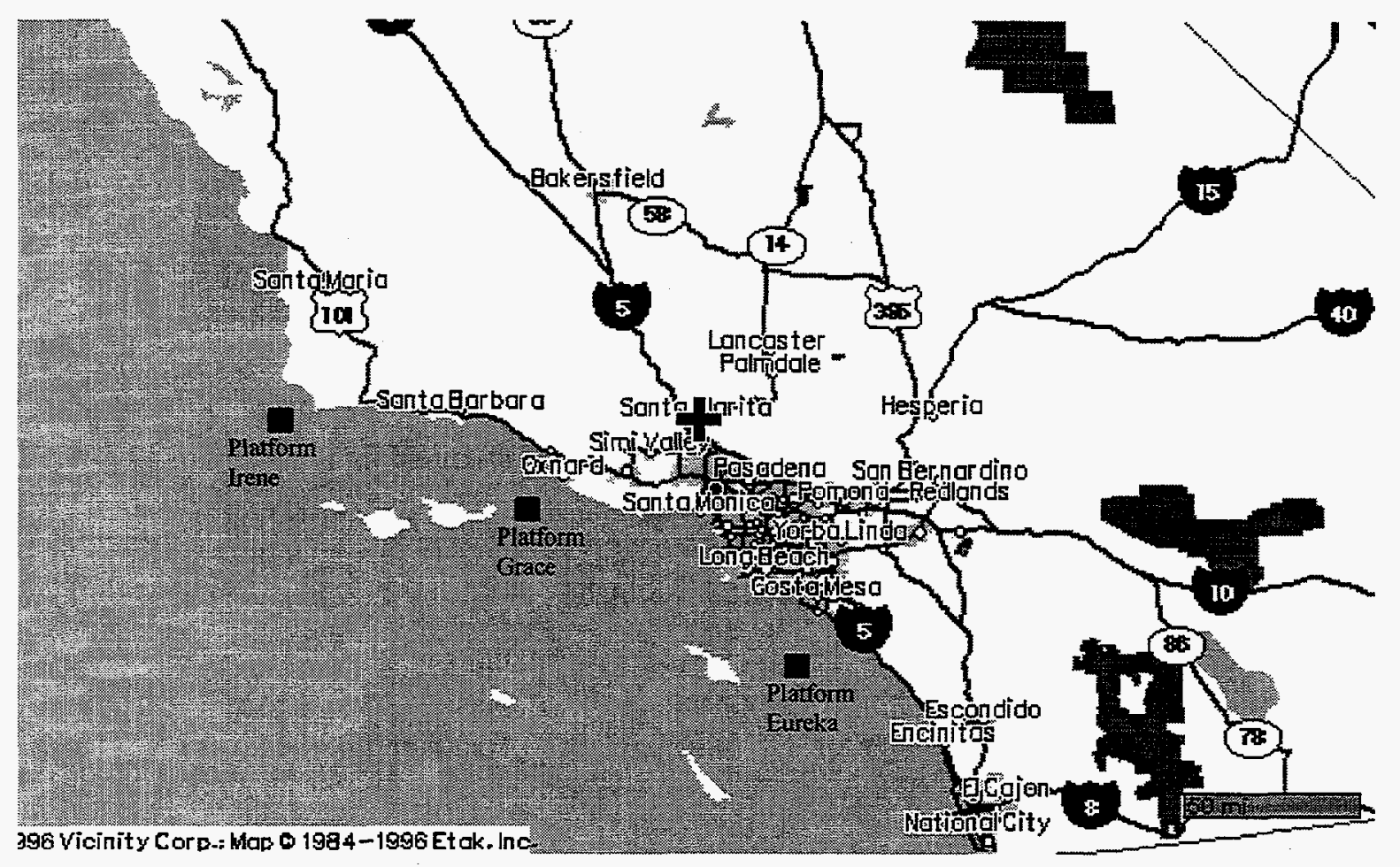

Figure IX: California coast and probe locations

\section{VI.1 Sunday and Monday, July 9 and 10, 1995}

We arrived at the Long Beach pier at approximately 4:00 a.m. on July 9, and promptly headed toward Platform Eureka. We arrived at the platform around 6:00 a.m., ready to begin the installation of the first probe. The weather was sunny and calm. This was a good sign. We lowered the installation cage to the seafloor, 693 feet below, and activated the vibrocorer to begin the penetration into the seafloor. We were able to watch this on the monitor thanks to the ROV camera. The vibrocorer ran for two seconds and died. We saw bubbles coming from one side of the motors and suspected we had a water leak. The probe was embedded about four feet into the seafloor. It was decided to pull up on the crane, removing the probe and cage back to the boat. Upon inspection of the vibrocorer, we had indeed lost a seal and burned out one of the motors. We decided to try again using the one remaining motor. Once on the bottom, we again activated the vibrocorer. The remaining motor died after a couple of seconds, with the probe embedded about six feet. We tried 
pulling up the probe and cage assembly. We inspected our hardware upon retrieval. The vibrocorer had again lost a seal, and now both motors were gone. The probe had sustained damage, as well. During the retrieval process, the protective cover where the coretube attaches, broke free, pulling out all the inserts in the tail section. The cable was also damaged at the $90^{\circ}$ elbow, a small tear in the sleeving. APM did some quick calling and found us a vibrocorer in Long Beach which was available for a price. That afternoon we headed back to the Long Beach pier and picked up the new vibrocorer and an operator. We spent the night on the boat at the pier and headed out for Eureka at 4:00 a.m. the next morning.

\section{VI.2 Tuesday, July 11, 1995}

At 6:00 a.m., we gathered for the mandatory operations meeting and discussed the days events. Luck was with us this day, as we successfully deployed the first probe at Eureka. The new vibrocorer embedded the probe, SN 01, seven feet into the seafloor. The cable was laid on the floor on its way to the underwater J-tube. It was then pulled up the J-tube by APM personnel and positioned into the previously installed junction box. Leslie Monahan, of MMS, did an electrical checkout of the cable and everything checked out fine. Sandia personnel were not allowed to go onto the platform, so the cable was stowed inside the junction box. We would return later that year to do the final topside installations. Around 9:30 p.m. that evening we began the eight hour journey towards Grace.

\section{VI.3 Wednesday, July 12, 1995}

We arrived at Grace around 5:30, in time for our 6:00 a.m. meeting and ready to begin the day. The ROV was sent down to look at the instrumentation tubes, and to evaluate the condition of the preexisting feeder line. The ROV tried to pull the feeder line through, but the line was wedged. An adjacent tube was tried, but it too, was clogged. We had no way of bringing our cables up to the junction box. Our goal at Grace was to install two probes, approximately $90^{\circ}$ apart from each other. This meant we would need extra room in the instrumentation tubes to allow for two cables to pass up. The instrumentation tubes at Grace were quite small in diameter in comparison to the other platforms. APM spent the day trying to unclog the instrumentation tubes. A hydroblaster was used to blast through the instrumentation tube at high pressure, eventually clearing the tube around 9:30 that evening. No probes were installed that day, but we were able to repair the probe and cable that were damaged earlier at Eureka. We spent the night moored up along the platform, ready to install at first light.

\section{VI.4 Thursday, July 13, 1995}

First thing in the morning, we successfully installed the first probe at Grace, SN-03, approximately three feet into the seafloor. The seafloor must have been extremely hard here, because continual vibrocoring did not embed the probe any farther, and it was decided to stop. The second probe was installed, $\mathrm{SN}-04$, approximately seven feet in, but evaluation of the electrical signals from the cable determined that two-of the three accelerometers had quit working. It was decided not to pull up the two probe cables in the instrumentation tube and risk getting them stuck in the smaller instrumentation tubes, since one of the units was not functioning properly. We were able to get one cable through the instrumentation tube successfully and the topside installation went smoothly. We were not $100 \%$ operational because of phone line problems. The unit was functioning properly, but could not be accessed via the modem dial-up process. We would return later that year to do the final modem hookups. 


\section{VI.5 Friday, July 14, 1995}

We steamed up the coast that evening, heading toward Irene and the final probe installation. Again, we had a successful probe installation, $\mathrm{SN}-02$. This time we embedded the probe about five feet. This riser had a large window cut in it and there were no problems retrieving the cable up to the junction box. Topside installation went flawlessly, no problems were encountered, and the unit was fully functional upon our departure that evening.

\section{Functional Testing}

\section{VII.1 Electronics Bench Testing}

The SEMS IV probe, signal conditioning and seismograph electronics were functionally tested and calibrated at Sandia Labs before shipment to the platforms for installation. These tests included gain calibration of all amplifier circuits in the panel and Quanterra constant current amplifiers. The results of this calibration testing are recorded in Section III. Functional tests of the probes and seismograph, including the long underwater cables, allowed measurement of system noise floor. These tests also verified that the transducers and the signal conditioning circuitry would operate over the long cables with no loading effects. Since the accelerometers are constant current devices, operation over long cables does not introduce significant sensitivity errors. The bench and cable tests demonstrated that the SEMS IV unit would operate with acceptable noise performance in the deployment scenario.

\section{VII.2 Pressure Testing (Sandia Facility)}

All four probes were pressure tested at an underwater pressure chamber located in Area III at Sandia National Laboratories. Each probe was suspended within the water filled chamber and pressurized to 800 psi for a twenty-four hour period. During each test, we monitored probe signals through the umbilical connector and noted no abnormalities during, or following, the test sequences. This test demonstrated that the SEMS IV unit could operate in the expected underwater pressures.

\section{VII.3 Vibration Testing (APM Facility)}

In May 1995, we delivered our first functional probe to APM for testing. We accomplished two things on this trip; system vibration testing and mechanical fit checks of APM's installation hardware. The first thing was to assemble the probe to the coretube assembly and install this onto the large steel installation cage. This provided us with valuable information on the assembly processes we could expect while on the boat. With the cage sitting upright, we proceeded to do our vibration testing. We activated the vibrocorer unit and proceeded to embed the probe into the soil at the APM office. Duration for this test was approximately one minute. The test was then repeated three more times. During the test we monitored probe signals through the umbilical connector, and noted no abnormalities during or following the test sequences. This test demonstrated that the SEMS IV unit could survive the harsh vibration environment of the vibrocorer and provided us with a workmanship testbed for our electronics assemblies. 


\section{Conclusion}

The SEMS IV has proven to be a robust, high quality, seismic instrument. The improved probe design and vibrocorer installation technique has proven sound in placing SEMS IV probes at platforms Eureka, Grace and Irene. The selection of Quanterra seismograph equipment allows for flexible operation recording high quality seismic event data. The inclusion of GPS interface and modem dial up capability to down load data will allow for remote monitoring and straightforward maintenance of the SEMS IV system.

Sandia Labs personnel will be visiting MMS this summer to train contractors in the operation and maintenance of SEMS IV. The transfer should be efficient and will allow MMS and other agencies interested in offshore platform seismic information to continue SEMS IV operation into the following years. 
This page intentionally left blank. 


\section{Appendices}

\section{IX.1 Appendix A. Electronics Schematics and Cabling Pin Outs}

Appendix A includes schematic drawings for all of the SEMS IV probe and control panel electronics. The schematic for the SEMS IV probe circuit board is, the control panel circuit board schematic is Figure $\mathrm{X}$. The cable schematic for the entire SEMS IV instrumentation system is provided in Figure XI. Note that cable numbers listed on Figure XII can be used as a key to search for pin out information for each of the SEMS IV cables which are defined in detail in Table XII-Table XXII. Note that cables \#1 through \#8 interconnect the probe, junction boxes and seismograph instruments and are routed externally between the instruments. The pin out information for these cables is included as Table VII-Table XIX. There are three more cables which interconnect functions inside the control panel. These cables are defined in Table XX-Table XXII. 


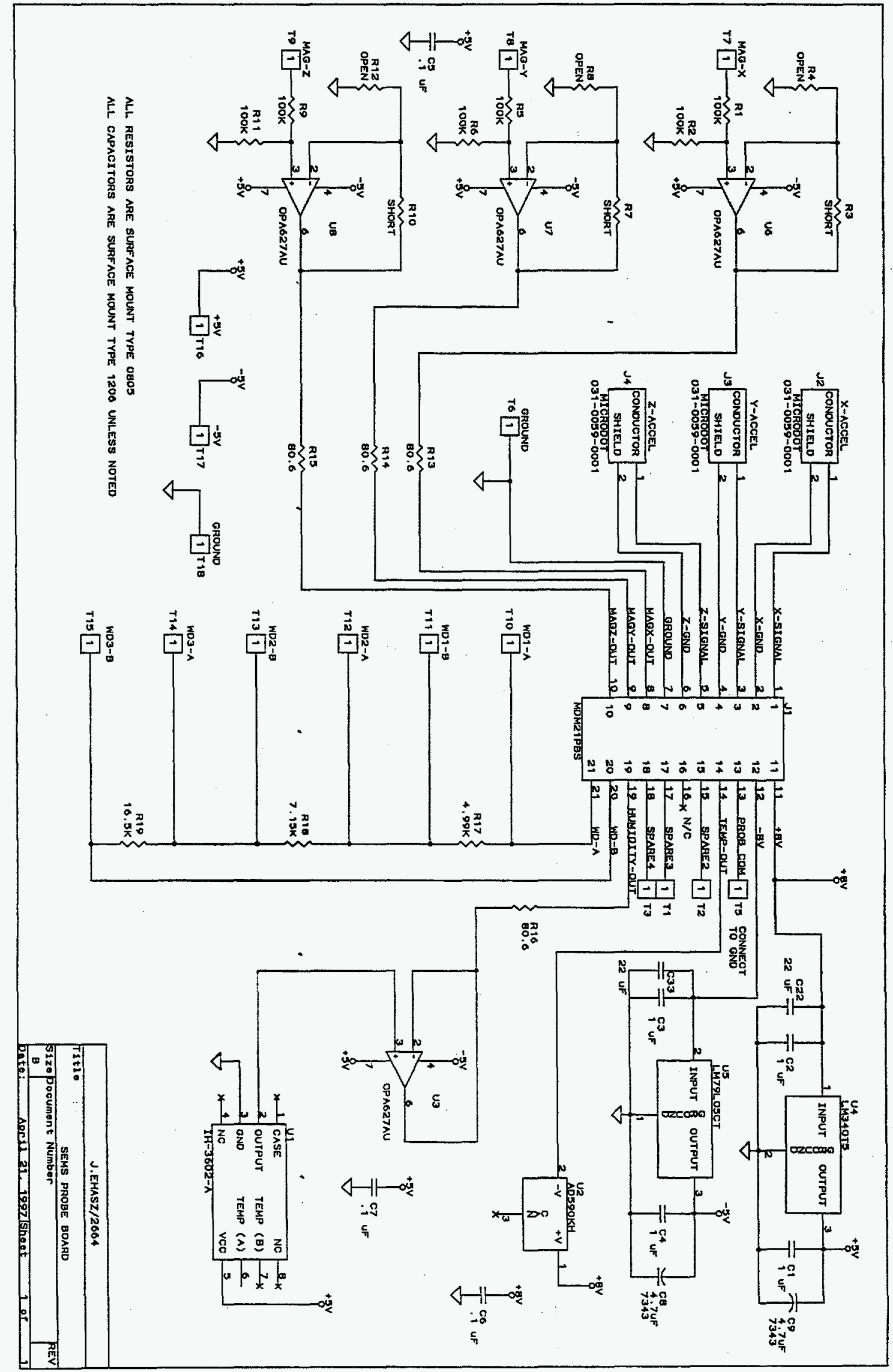




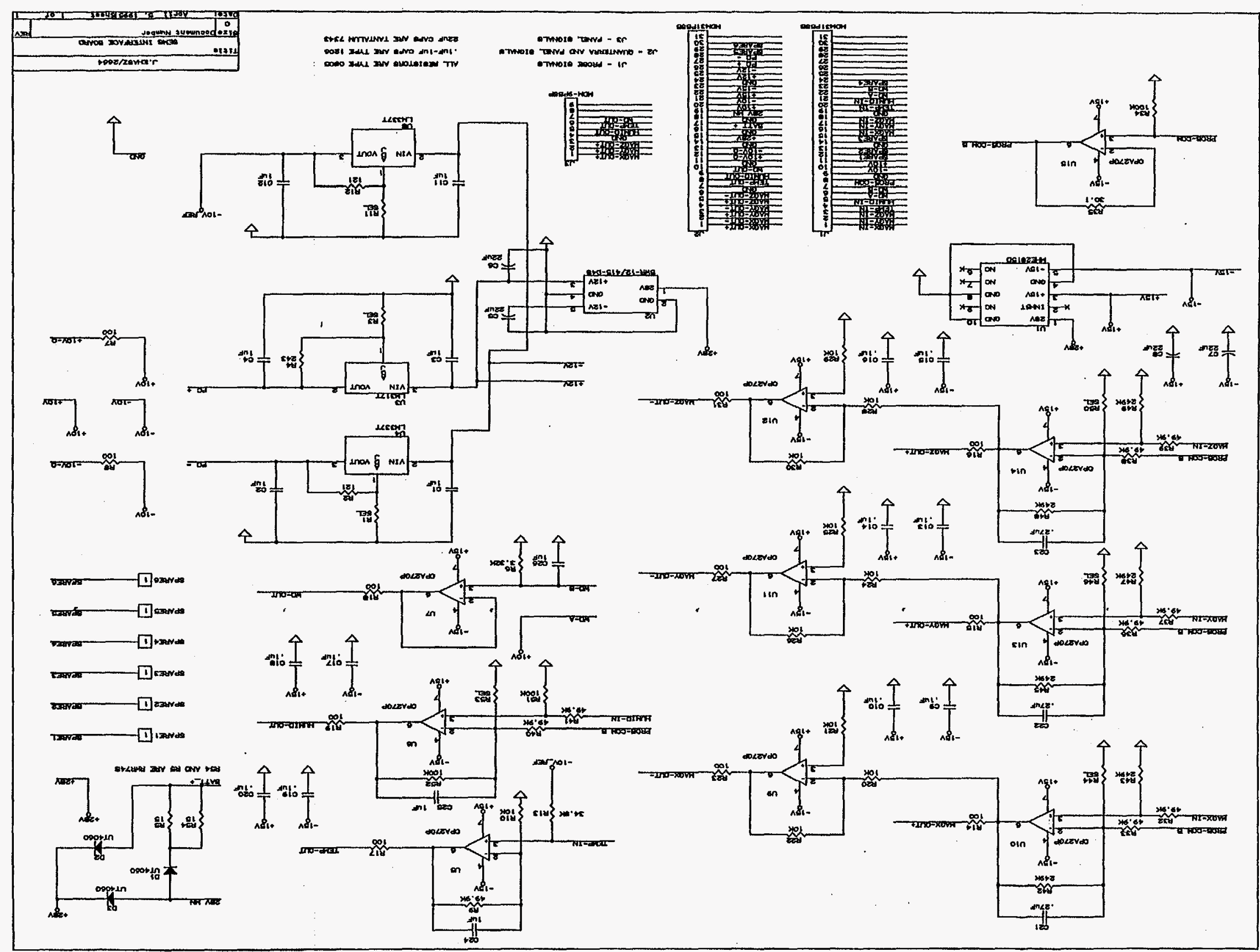




\section{SEMS IV CABLE DIAGRAM}

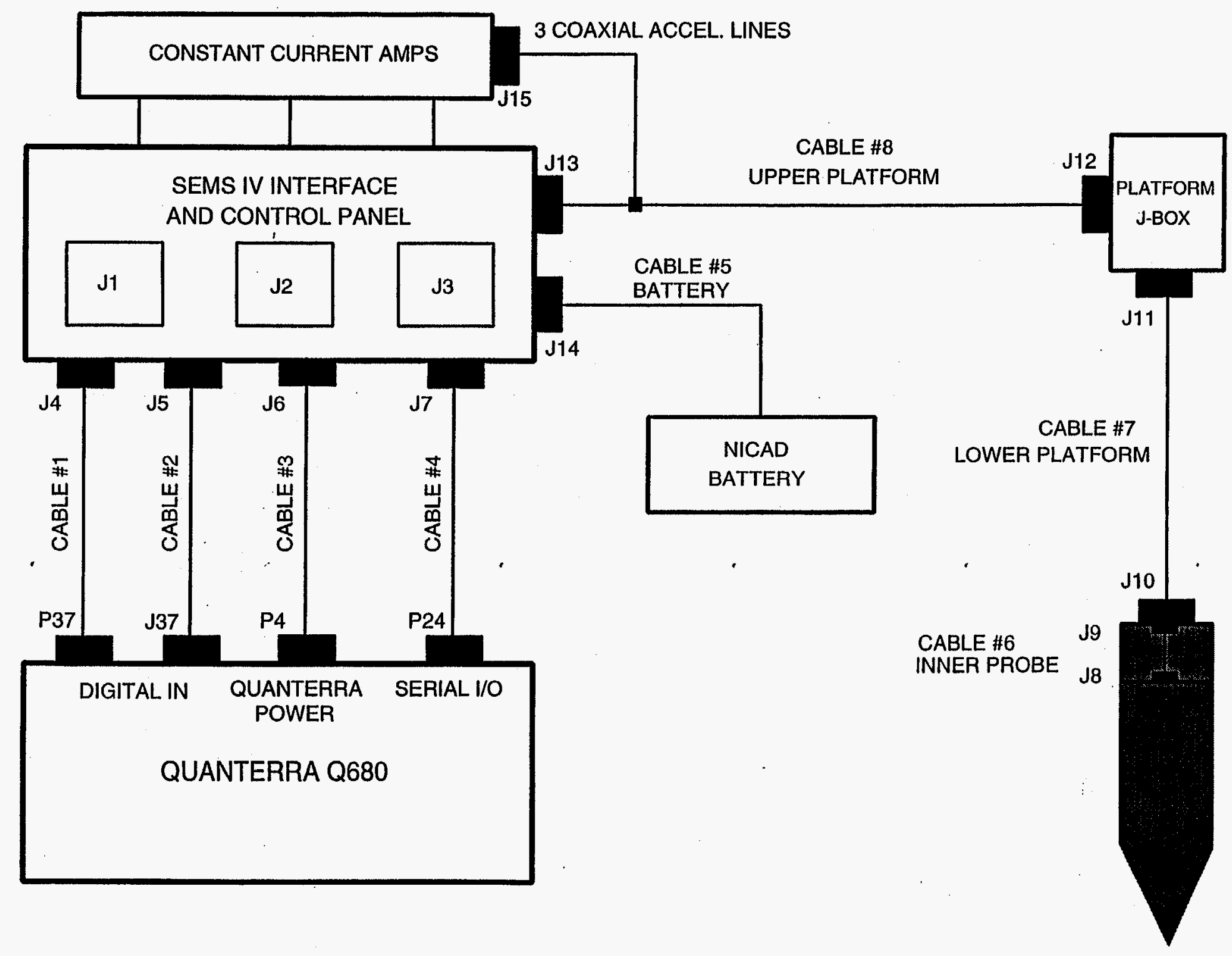


Table XII: Pin Out for Cable \#1

\begin{tabular}{|c|c|c|c|}
\hline Signal Name & $\begin{array}{c}\text { P37 } \\
\text { AMP-37S }\end{array}$ & $\begin{array}{c}\text { J4 } \\
\text { PTO-10-98S }\end{array}$ & $\begin{array}{c}\text { P1 } \\
\text { D25ML }\end{array}$ \\
\hline TEMP_OUT & 17 & A & N/C \\
\hline+10 V-Q & 16 & B & N/C \\
\hline -10 V-Q & 24 & C & N/C \\
\hline GROUND & 15 & D & N/C \\
\hline N/C & N/C & E & N/C \\
\hline N/C & N/C & F & N/C \\
\hline X-ACCEL + & 8 & N/C & 2 \\
\hline X-ACCEL - & 4 & N/C & 3 \\
\hline Y-ACCEL + & 7 & N/C & 4 \\
\hline Y-ACCEL - & 3 & N/C & 5 \\
\hline Z-ACCEL + & 6 & N/C & 6 \\
\hline Z-ACCEL - & 2 & N/C & 8 \\
\hline GROUND & 9 & N/C & 14 \\
\hline
\end{tabular}

Table XIII: Pin Out for Cable \#2

\begin{tabular}{|c|c|c|}
\hline Signal Name & $\begin{array}{c}\text { J37 } \\
\text { AMP-37P }\end{array}$ & $\begin{array}{c}\text { J5 } \\
\text { PTO-12-10S }\end{array}$ \\
\hline MAGX-OUT+ & $\mathbf{8}$ & $\mathrm{A}$ \\
\hline MAGX-OUT- & 4 & $\mathrm{~B}$ \\
\hline MAGY-OUT + & 7 & $\mathrm{C}$ \\
\hline MAGY-OUT- & 3 & $\mathrm{D}$ \\
\hline MAGZ-OUT + & 6 & $\mathrm{E}$ \\
\hline MAGZ-OUT- & 2 & $\mathrm{~F}$ \\
\hline GROUND & 9 & $\mathrm{G}$ \\
\hline HUMDITY-OUT & 17 & $\mathrm{H}$ \\
\hline WATER DETECT-OUT & 16 & $\mathrm{~J}$ \\
\hline GROUND & 15 & $\mathrm{~K}$ \\
\hline
\end{tabular}

Table XIV: Pin Out for Cable \#3

\begin{tabular}{|c|c|c|}
\hline Signal Name & $\begin{array}{c}\text { P4 } \\
\text { AMP-4S }\end{array}$ & $\begin{array}{c}\text { J6 } \\
\text { PTO-10-98S }\end{array}$ \\
\hline$+28 \mathrm{~V}$ & 1 & $\mathrm{~A}$ \\
\hline +28V RETURN & 2 & B \\
\hline N/C & 3 & C \\
\hline N/C & 4 & D \\
\hline
\end{tabular}


Table XV: Pin Out for Cable \#4

\begin{tabular}{|c|c|c|}
\hline Signal Name & $\begin{array}{c}\text { P24 } \\
\text { AMP-24S }\end{array}$ & $\begin{array}{c}\text { J7 } \\
\text { PTO-12-10P }\end{array}$ \\
\hline TX & 6 & A \\
\hline RX & 2 & B \\
\hline RETURN & 10 & $\mathrm{C}$ \\
\hline DTR & 12 & $\mathrm{D}$ \\
\hline DCD & 13 & E \\
\hline N/C & N/C & F \\
\hline N/C & N/C & G \\
\hline N/C & N/C & H \\
\hline N/C & N/C & J \\
\hline N/C & N/C & K \\
\hline
\end{tabular}

Table XVI: Pin Out for Cable \#5

\begin{tabular}{|c|c|c|}
\hline Signal Name & $\begin{array}{c}\text { J14 } \\
\text { PTO-16-11S }\end{array}$ & $\begin{array}{c}\text { HARDWIRED } \\
\text { TO BATTERY }\end{array}$ \\
\hline BATTERY + & $\mathrm{A}$ & RED \\
\hline RETURN & $\mathrm{B}$ & BLACK \\
\hline
\end{tabular}

Table XVII: Pin Out for Cable \#6

\begin{tabular}{|c|c|c|}
\hline Signal Name & $\begin{array}{c}\text { J8 } \\
\text { MDM-21S }\end{array}$ & $\begin{array}{c}\text { J9 } \\
\text { MINL-20-FCR }\end{array}$ \\
\hline X-ACCEL (SIG) & 1 & 1 \\
\hline X-ACCEL (COM) & 2 & 2 \\
\hline Y-ACCEL (SIG) & 3 & 3 \\
\hline Y-ACCEL (COM) & 4 & 4 \\
\hline Z-ACCEL (SIG) & 5 & 5 \\
\hline Z-ACCEL (COM) & 6 & 6 \\
\hline GROUND & 7 & 7 \\
\hline MAGX-OUT & 8 & 8 \\
\hline MAGY-OUT & 9 & 9 \\
\hline MAGZ-OUT & 10 & 10 \\
\hline$+8 \mathrm{~V} \mathrm{IN}$ & 11 & 11 \\
\hline$-8 \mathrm{~V} \mathbb{N}$ & 12 & 12 \\
\hline SPARE1 & 13 & 13 \\
\hline TEMP-OUT & 14 & 14 \\
\hline SPARE 2 & 15 & 15 \\
\hline $\mathrm{N} / \mathrm{C}$ & 16 & $\mathrm{~N} / \mathrm{C}$ \\
\hline SPARE 3 & 17 & 16 \\
\hline SPARE 4 & 18 & 17 \\
\hline HUMIDITY-OUT & 19 & 18 \\
\hline WATER DETECT (A) & 20 & 19 \\
\hline WATER DETECT (B) & 21 & 20 \\
\hline
\end{tabular}


Table XVIII: Pin Out for Cable \#7

\begin{tabular}{|c|c|c|}
\hline Signal Name & $\begin{array}{c}\text { J10 } \\
\text { MINL-20-CCP-R/A }\end{array}$ & $\begin{array}{c}\text { J11 } \\
\text { MINL-20-CCP }\end{array}$ \\
\hline X-ACCEL (SIG)* & $\overline{1}$ & 1 \\
\hline X-ACCEL $(\mathrm{COM})^{*}$ & 2 & 2 \\
\hline Y-ACCEL (SIG)* ${ }^{*}$ & 3 & 3 \\
\hline Y-ACCEL $(\mathrm{COM})^{*}$ & 4 & 4 \\
\hline Z-ACCEL (SIG)* & 5 & 5 \\
\hline Z-ACCEL (COM)* & 6 & 6 \\
\hline GROUND & 7 & 7 \\
\hline MAGX-OUT & 8 & 8 \\
\hline MAGY-OUT & 9 & $\overline{9}$ \\
\hline MAGZ-OUT & 10 & 10 \\
\hline$+8 \mathrm{~V} \mathrm{IN}$ & 11 & 11 \\
\hline$-8 \mathrm{~V} \mathrm{IN}$ & 12 & 12 \\
\hline SPARE 1 & 13 & 13 \\
\hline TEMP-OUT & 14 & 14 \\
\hline SPARE 2 & 15 & 15 \\
\hline SPARE 3 & 16 & 16 \\
\hline SPARE 4 & 17 & 17 \\
\hline HUMIDITY OUT & 18 & 18 \\
\hline WATER DETECT (A) & 19 & 19 \\
\hline WATER DETECT (B) & 20 & 20 \\
\hline
\end{tabular}

*Note: Accelerometer signals are on RG316 Coax 
Table XIX: Pin Out for Cable \#8

\begin{tabular}{|c|c|c|c|}
\hline Signal Name & $\begin{array}{c}\text { J12 } \\
\text { MINL-20-FCR }\end{array}$ & $\begin{array}{c}\mathbf{J 1 5} \\
\text { TWINAXIAL } \\
\text { CONNECTORS }\end{array}$ & $\begin{array}{c}\text { J13 } \\
\text { PTO-16-26P }\end{array}$ \\
\hline X-ACCEL (SIG)* & 1 & $\overline{\text { TA-1 }}$ & $\mathrm{N} / \mathrm{C}$ \\
\hline X-ACCEL (COM)* & 2 & TA-1 & $\mathrm{N} / \mathrm{C}$ \\
\hline Y-ACCEL (SIG)* & 3 & TA-2 & $\mathrm{N} / \mathrm{C}$ \\
\hline Y-ACCEL $(\mathrm{COM})^{*}$ & $\overline{4}$ & TA-2 & $\mathrm{N} / \mathrm{C}$ \\
\hline Z-ACCEL (SIG)* & 5 & TA-3 & $\mathrm{N} / \mathrm{C}$ \\
\hline Z-ACCEL (COM)* & 6 & TA-3 & $\mathrm{N} / \mathrm{C}$ \\
\hline GROUND & 7 & $\mathrm{~N} / \mathrm{C}$ & $\bar{J}$ \\
\hline MAGX-OUT & 8 & $\mathrm{~N} / \mathrm{C}$ & $\bar{A}$ \\
\hline MAGY-OUT & 9 & $\mathrm{~N} / \mathrm{C}$ & $\bar{B}$ \\
\hline MAGZ-OUT & 10 & $\mathrm{~N} / \mathrm{C}$ & $\mathrm{C}$ \\
\hline$+8 \mathrm{VIN}$ & 11 & $\mathrm{~N} / \mathrm{C}$ & $\bar{K}$ \\
\hline$-8 \mathrm{~V} \mathbb{N}$ & 12 & $\mathrm{~N} / \mathrm{C}$ & $\overline{\mathrm{L}}$ \\
\hline$\overline{\text { SPARE } 1}$ & 13 & $\mathrm{~N} / \mathrm{C}$ & $\overline{\mathrm{H}}$ \\
\hline TEMP-OUT & 14 & $\mathrm{~N} / \mathrm{C}$ & $\overline{\mathrm{D}}$ \\
\hline SPARE 2 & 15 & $\mathrm{~N} / \mathrm{C}$ & $\bar{M}$ \\
\hline SPARE 3 & 16 & $\mathrm{~N} / \mathrm{C}$ & $\bar{N}$ \\
\hline SPARE 4 & 17 & $\mathrm{~N} / \mathrm{C}$ & $\overline{\mathrm{R}}$ \\
\hline HUMIDITY OUT & 18 & $\mathrm{~N} / \mathrm{C}$ & $\bar{E}$ \\
\hline WATER DETECT (A) & 19 & $\mathrm{~N} / \mathrm{C}$ & $\bar{G}$ \\
\hline WATER DETECT (B) & 20 & $\mathrm{~N} / \mathrm{C}$ & $\overline{\mathrm{F}}$ \\
\hline
\end{tabular}


Table XX: Pin Out Internal Control Panel Cable J1

\begin{tabular}{|c|c|c|}
\hline Signal Name & $\begin{array}{c}\text { J1 } \\
\text { MDM-31S }\end{array}$ & $\begin{array}{c}\text { CONNECTS } \\
\text { TO }\end{array}$ \\
\hline MAGX-IN & 1 & J13-A \\
\hline MAGY-IN & 2 & J13-B \\
\hline MAGZ-IN & 3 & $\mathrm{J13-C}$ \\
\hline TEMP-IN & 4 & J13-D \\
\hline HUMIDITY-IN & 5 & J13-E \\
\hline WATER DETECT (A) & 6 & J13-F \\
\hline WATER DETECT (B) & 7 & $\overline{J 13-G}$ \\
\hline PROBE COM & $\overline{8}$ & $\overline{\mathrm{J} 13-\mathrm{H}}$ \\
\hline GROUND & 9 & J13-J \\
\hline$-10 \mathrm{VIN}$ & 10 & $\mathrm{~J} 13-\mathrm{K}$ \\
\hline$+10 \mathrm{~V} \mathrm{IN}$ & 11 & J13-L \\
\hline$\overline{\text { SPARE } 1}$ & 12 & $\overline{\mathrm{J} 13-\mathrm{M}}$ \\
\hline SPARE 2 & 13 & J13-N \\
\hline GROUND & 14 & J13-P \\
\hline SPARE 3 & 15 & J13-R \\
\hline MAGX-IN & 16 & PANEL \\
\hline MAGY-IN & 17 & PANEL \\
\hline MAGZ-IN & 18 & PANEL \\
\hline GROUND & 19 & PANEL \\
\hline TEMP-IN & 20 & PANEL \\
\hline HUMIDITY-IN & 21 & PANEL \\
\hline WATER DETECT (A) & 22 & PANEL \\
\hline WATER DETECT (B) & 23 & PANEL \\
\hline$\overline{\text { SPARE } 4}$ & 24 & $\mathrm{~J} 13-\mathrm{a}$ \\
\hline $\mathrm{N} / \mathrm{C}$ & 25 & $\mathrm{~J} 13-\mathrm{b}$ \\
\hline $\mathrm{N} / \mathrm{C}$ & 26 & J13-c \\
\hline
\end{tabular}


Table XXI: Pin Out Internal Control Panel Cable J2

\begin{tabular}{|c|c|c|}
\hline Signal Name & $\begin{array}{c}\mathbf{J 1} \\
\mathrm{MDM}-31 \mathrm{~S}\end{array}$ & $\begin{array}{c}\text { CONNECTS } \\
\text { TO }\end{array}$ \\
\hline MAGX-OUT+ & 1 & J5-A \\
\hline MAGX-OUT- & 2 & J5-B \\
\hline MAGY-OUT+ & 3 & J5-C \\
\hline MAGY-OUT- & 4 & J5-D \\
\hline MAGZ-OUT+ & 5 & J5-E \\
\hline MAGZ-OUT- & $\overline{6}$ & J5-F \\
\hline GROUND & 7 & J5-G \\
\hline TEMP OUT & 8 & $\mathrm{~J} 4-\mathrm{A}$ \\
\hline HUMIDITY OUT & 9 & $\mathrm{~J} 5-\mathrm{H}$ \\
\hline WATER DETECT OUT & 10 & J5-J \\
\hline GROUND & 11 & $\mathrm{~J} 5-\mathrm{K}$ \\
\hline$+10 \mathrm{~V}-\mathrm{Q}$ & 12 & J4-B \\
\hline$-10 V-Q$ & 13 & J4-C \\
\hline GROUND & 14 & J4-D \\
\hline$+28 \mathrm{~V}$ & 15 & J6-A \\
\hline GROUND & 16 & J6-B \\
\hline BATTERY + & 17 & J14-A \\
\hline GROUND & 18 & J14-B \\
\hline 28V MAIN & 19 & PANEL (S3) \\
\hline$+10 \mathrm{~V}$ & 20 & PANEL \\
\hline$-10 \mathrm{~V}$ & 21 & PANEL \\
\hline$+15 \mathrm{~V}$ & 22 & PANEL \\
\hline$-15 \mathrm{~V}$ & 23 & PANEL \\
\hline GROUND & 24 & PANEL \\
\hline$+12 \mathrm{~V}$ & 25 & PANEL \\
\hline$-12 \mathrm{~V}$ & 26 & PANEL \\
\hline PROBE CURRENT + & 27 & PANEL (S2) \\
\hline PROBE CURRENT - & 28 & PANEL (S2) \\
\hline SPARE 5 & 29 & PANEL \\
\hline SPARE 6 & 30 & PANEL \\
\hline $\mathrm{N} / \mathrm{C}$ & 31 & $\mathrm{~N} / \mathrm{C}$ \\
\hline
\end{tabular}

Table XXII: Pin Out Internal Control Panel Cable J3

\begin{tabular}{|c|c|c|}
\hline Signal Name & $\begin{array}{c}\text { J3 } \\
\text { MDM-9S }\end{array}$ & $\begin{array}{c}\text { CONNECTS } \\
\text { TO }\end{array}$ \\
\hline MAGX-OUT + & 1 & PANEL \\
\hline MAGY-OUT + & 2 & PANEL \\
\hline MAGZ-OUT+ & 3 & PANEL \\
\hline GROUND & 4 & PANEL \\
\hline HUMITIY OUT & 5 & PANEL \\
\hline TEMP OUT & 6 & PANEL \\
\hline WATER DETECT OUT & 7 & PANEL \\
\hline N/C & 8 & N/C \\
\hline N/C & 9 & N/C \\
\hline
\end{tabular}




\section{IX.2 Appendix B. Mechanical Fabrication Drawings}

Appendix B includes a complete copy of the drawings used to fabricate all the mechanical hardware for the Probe. The design was accomplished using Pro/Engineer design software. 


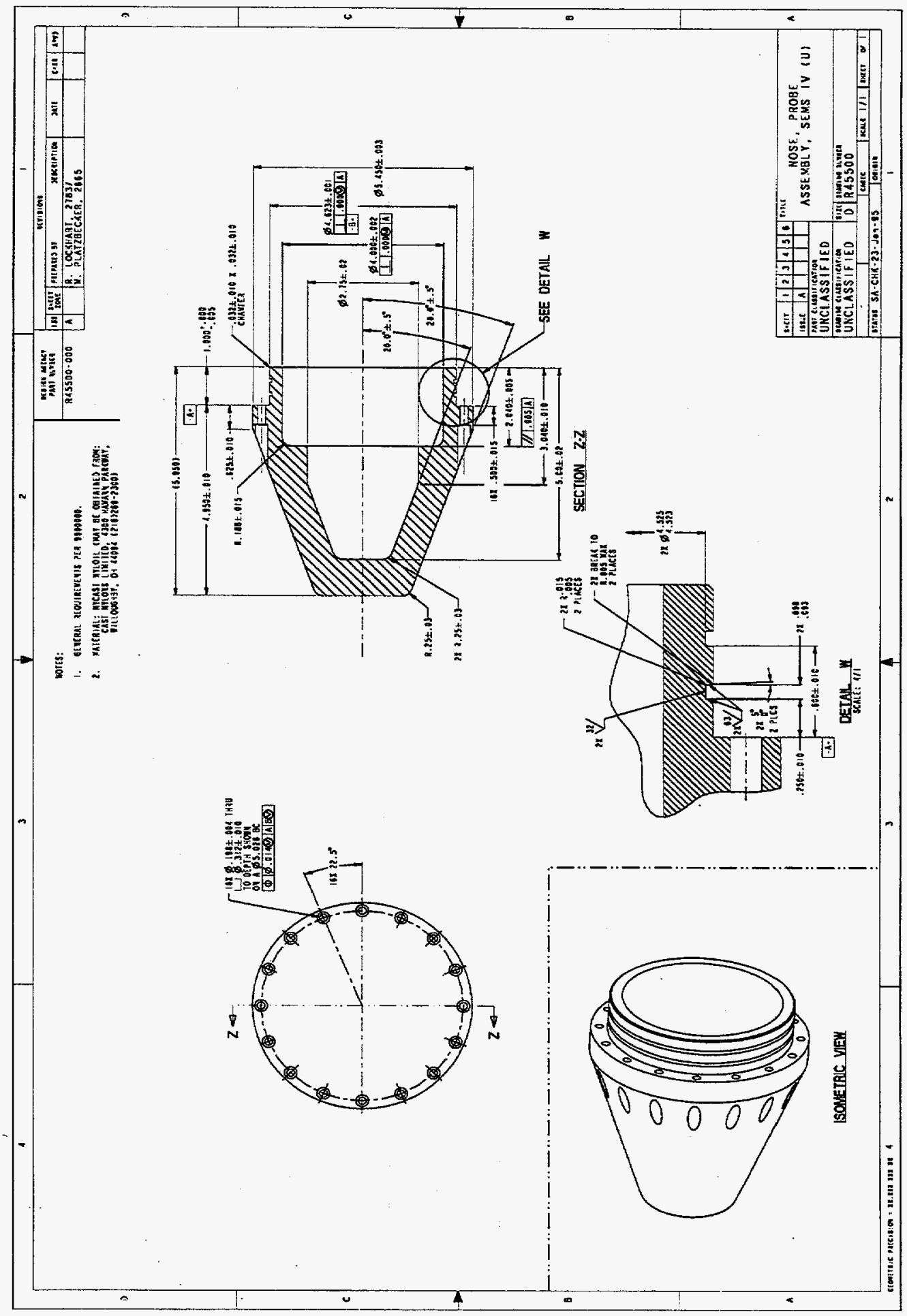

Figure XIII: Probe Nose 


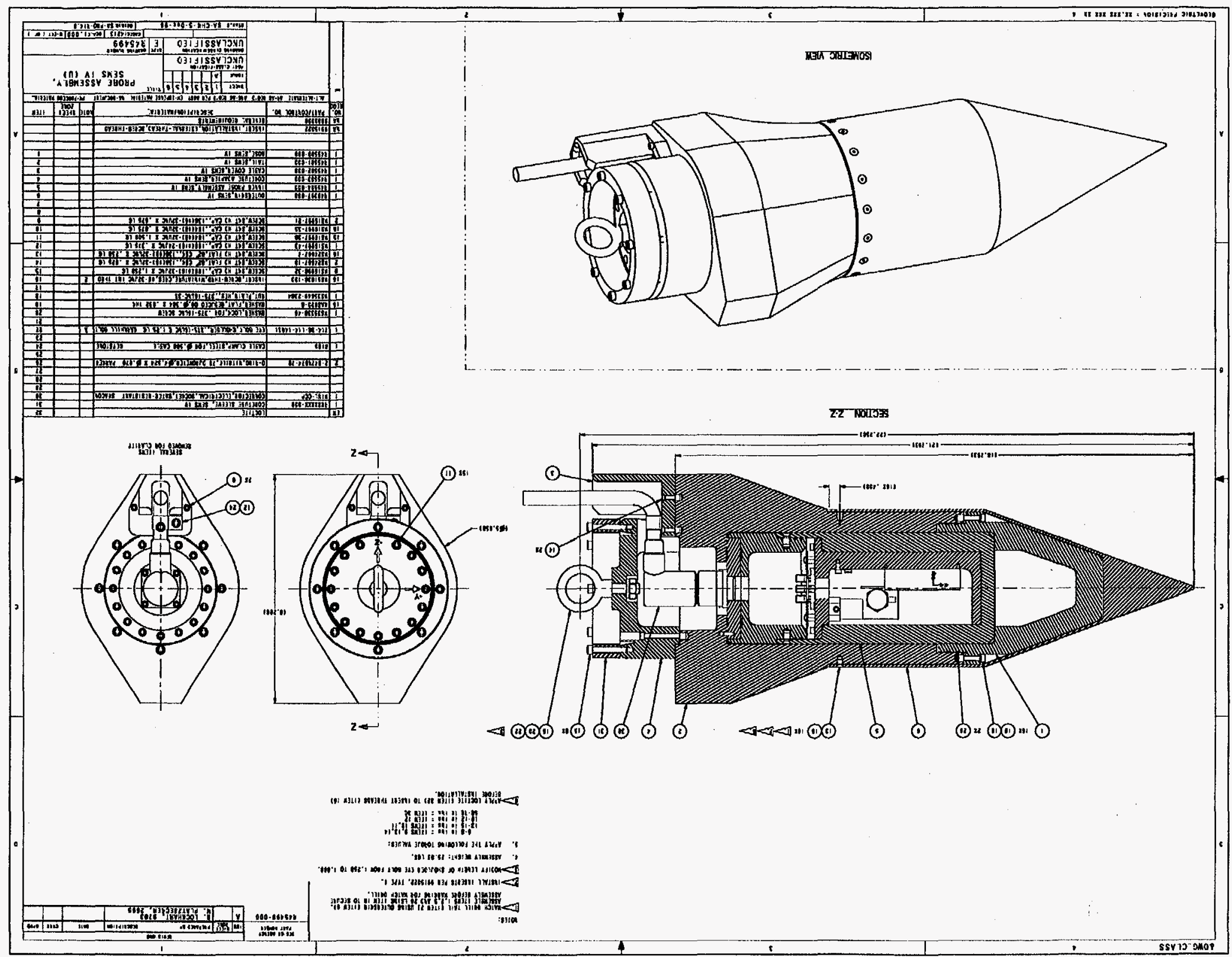




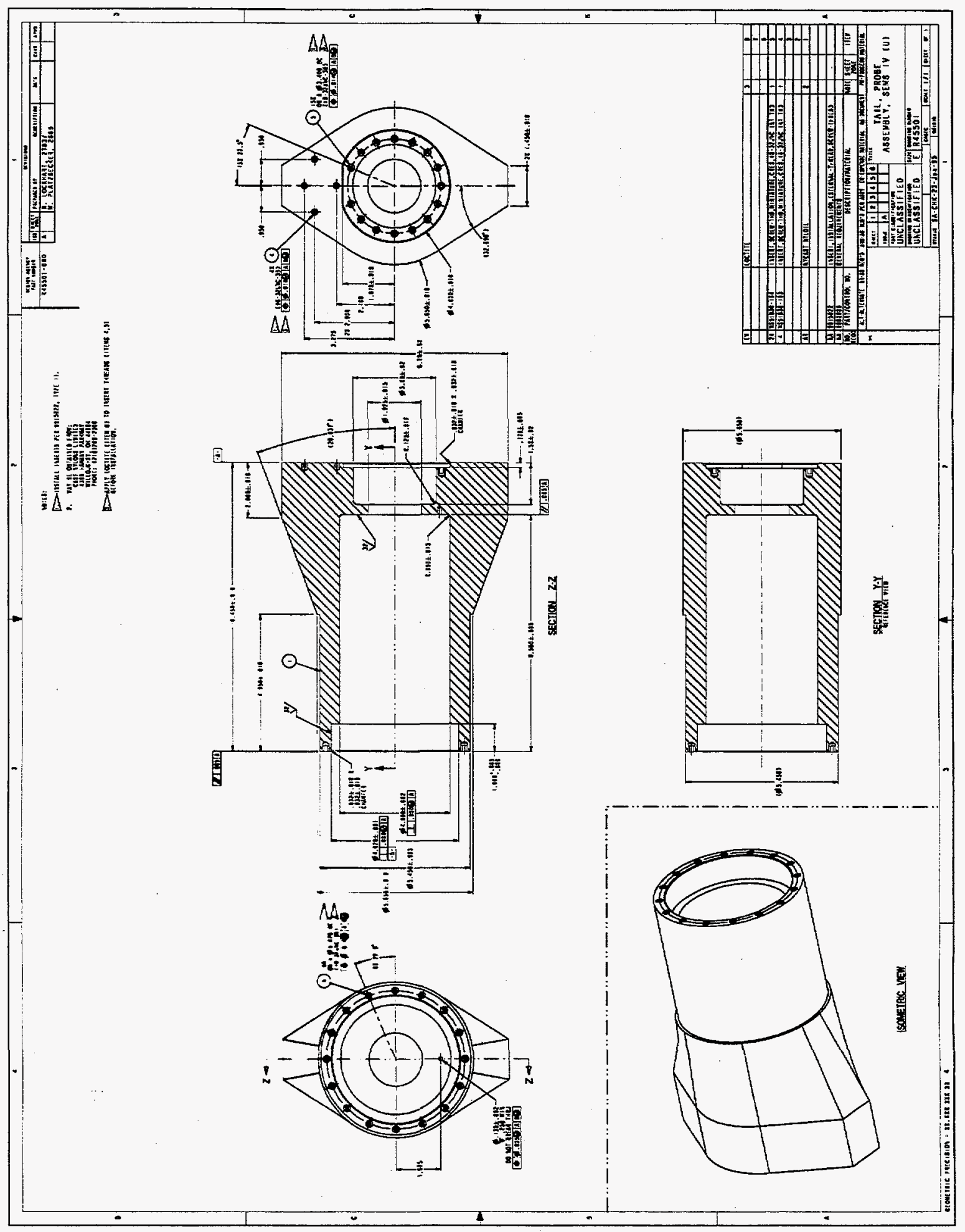

Figure XV: Probe Tail 


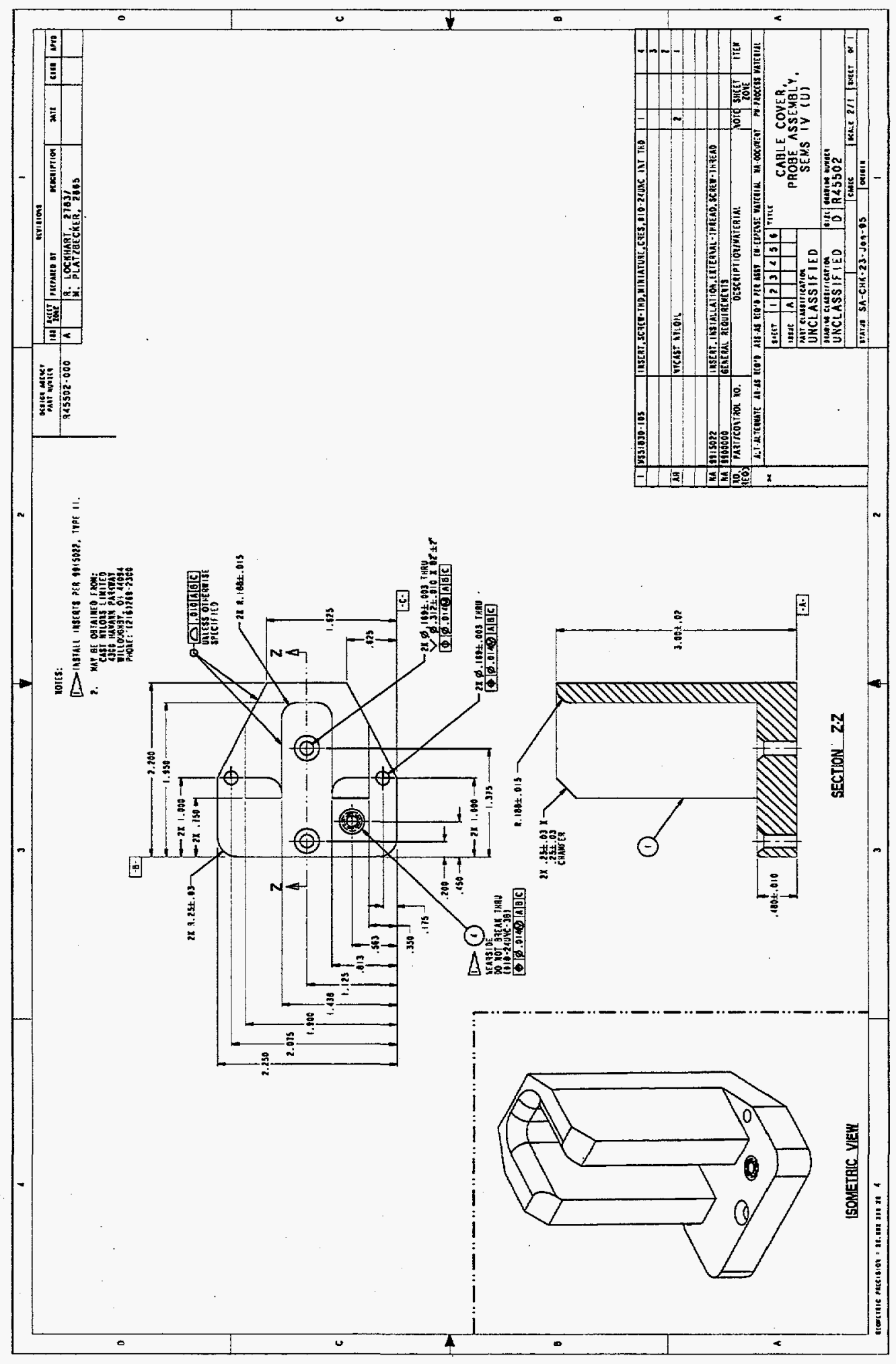

Figure XVI: Cable Cover 


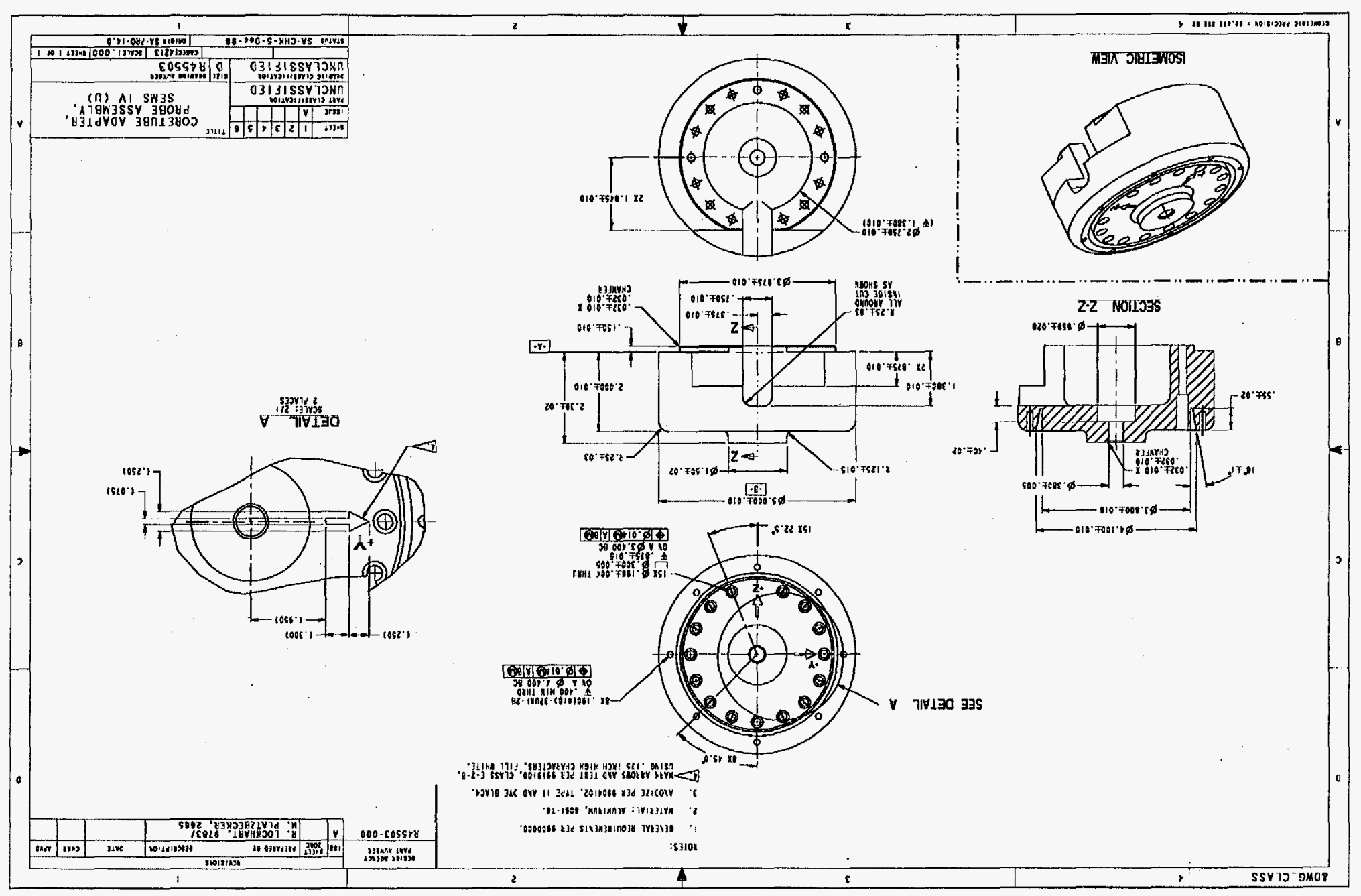

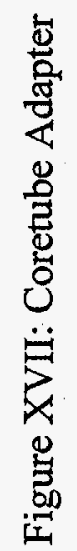




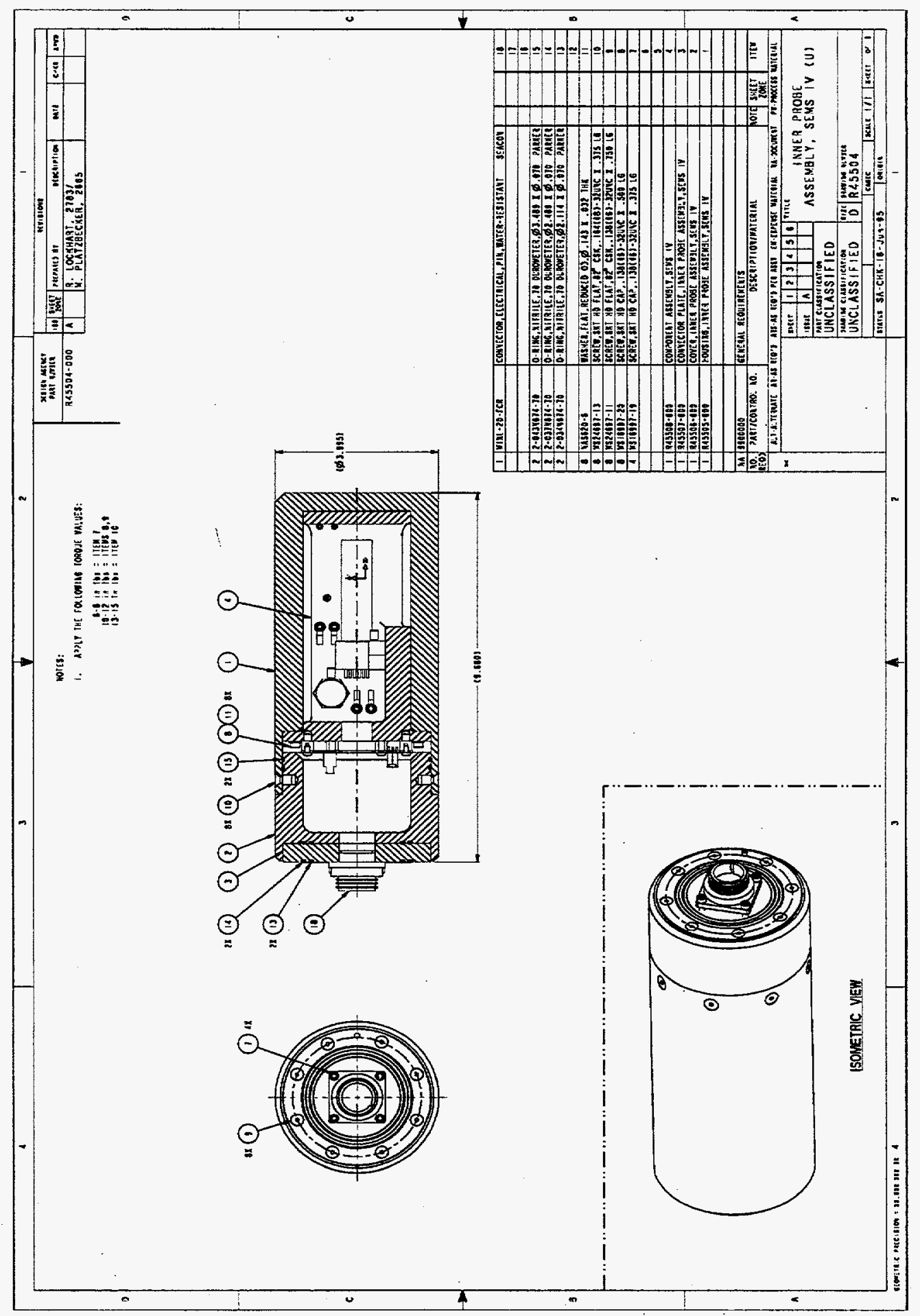

Figure XVIII: Inner Probe Assembly 


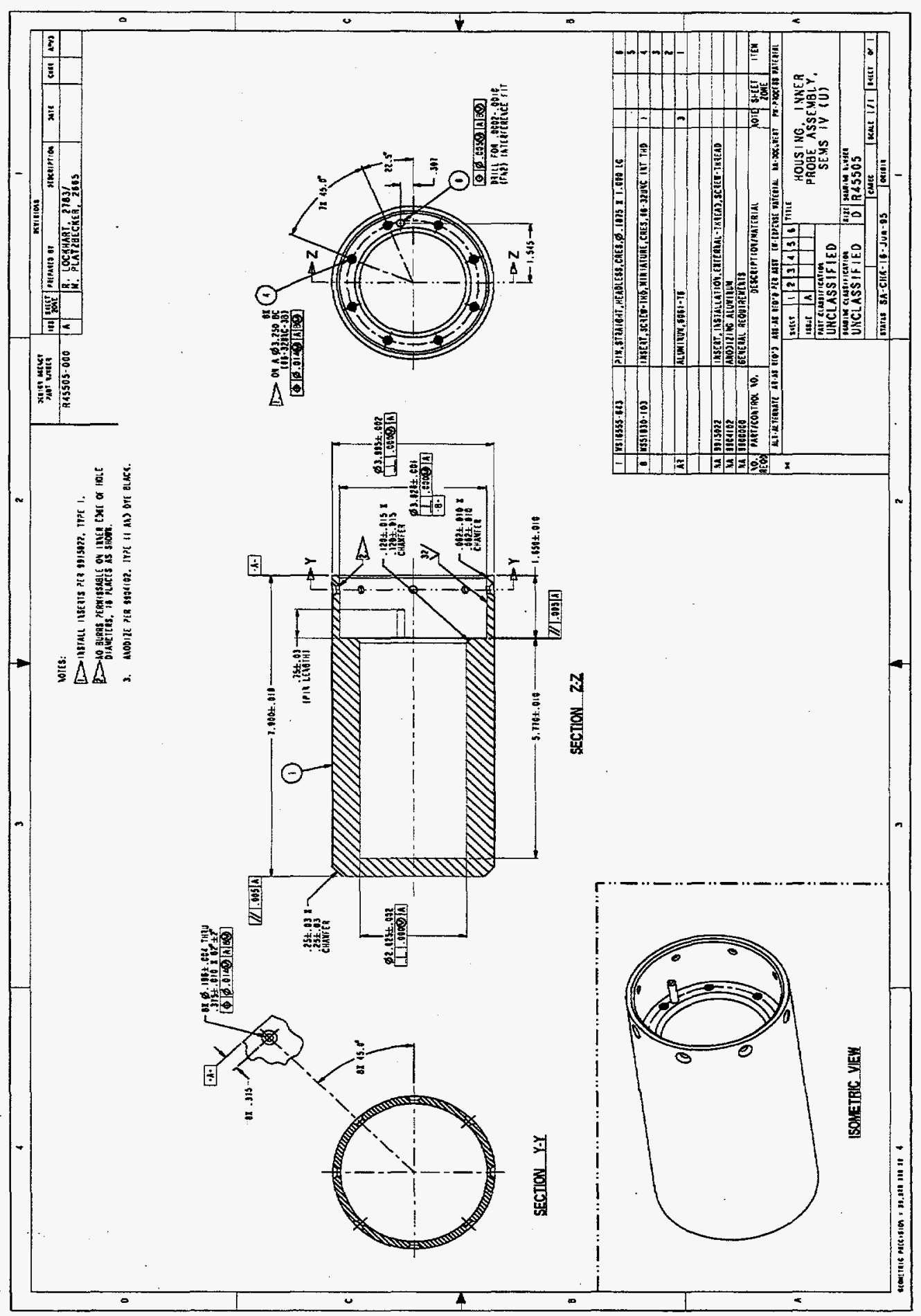

Figure XIX: Inner Housing 
เә

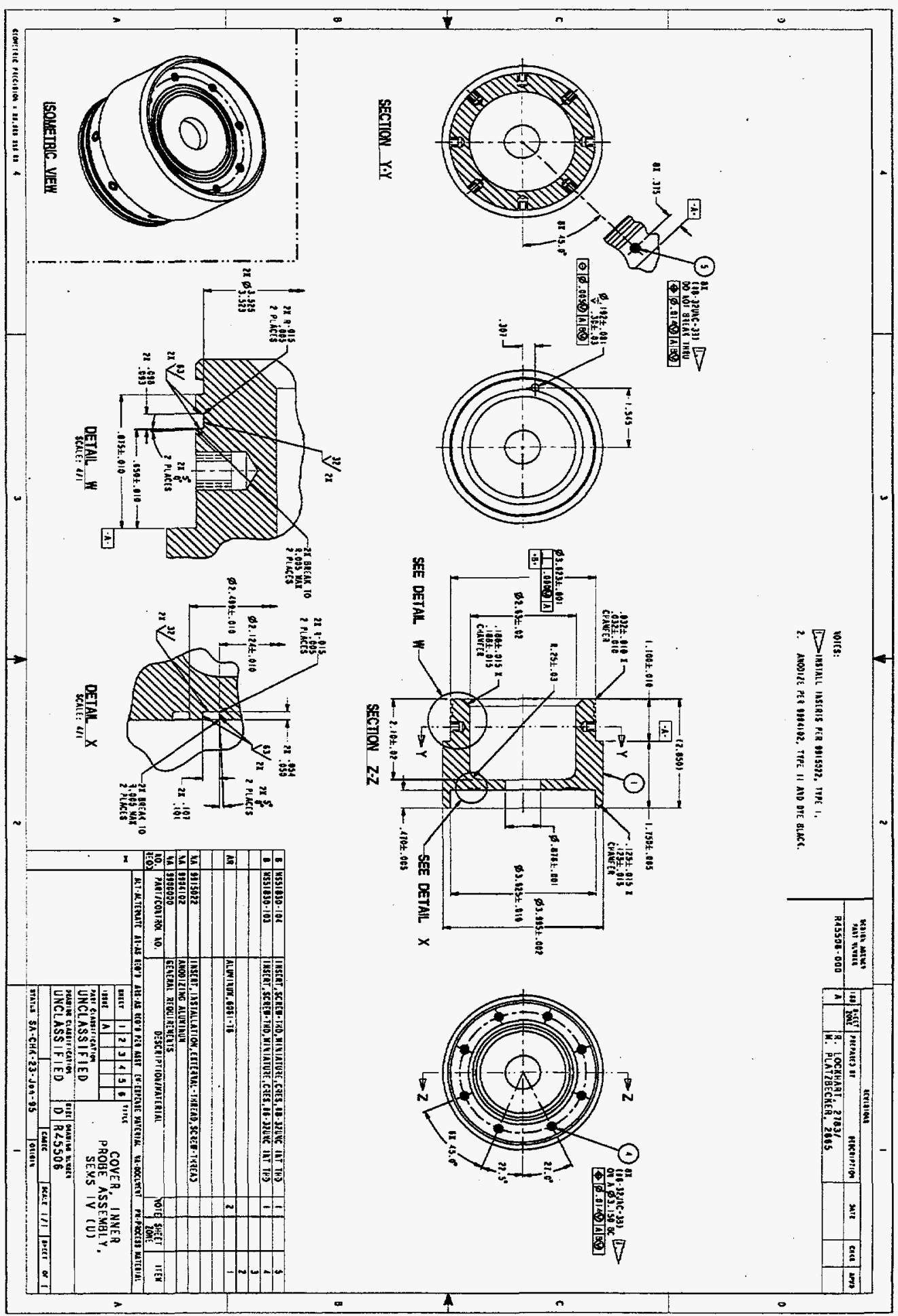




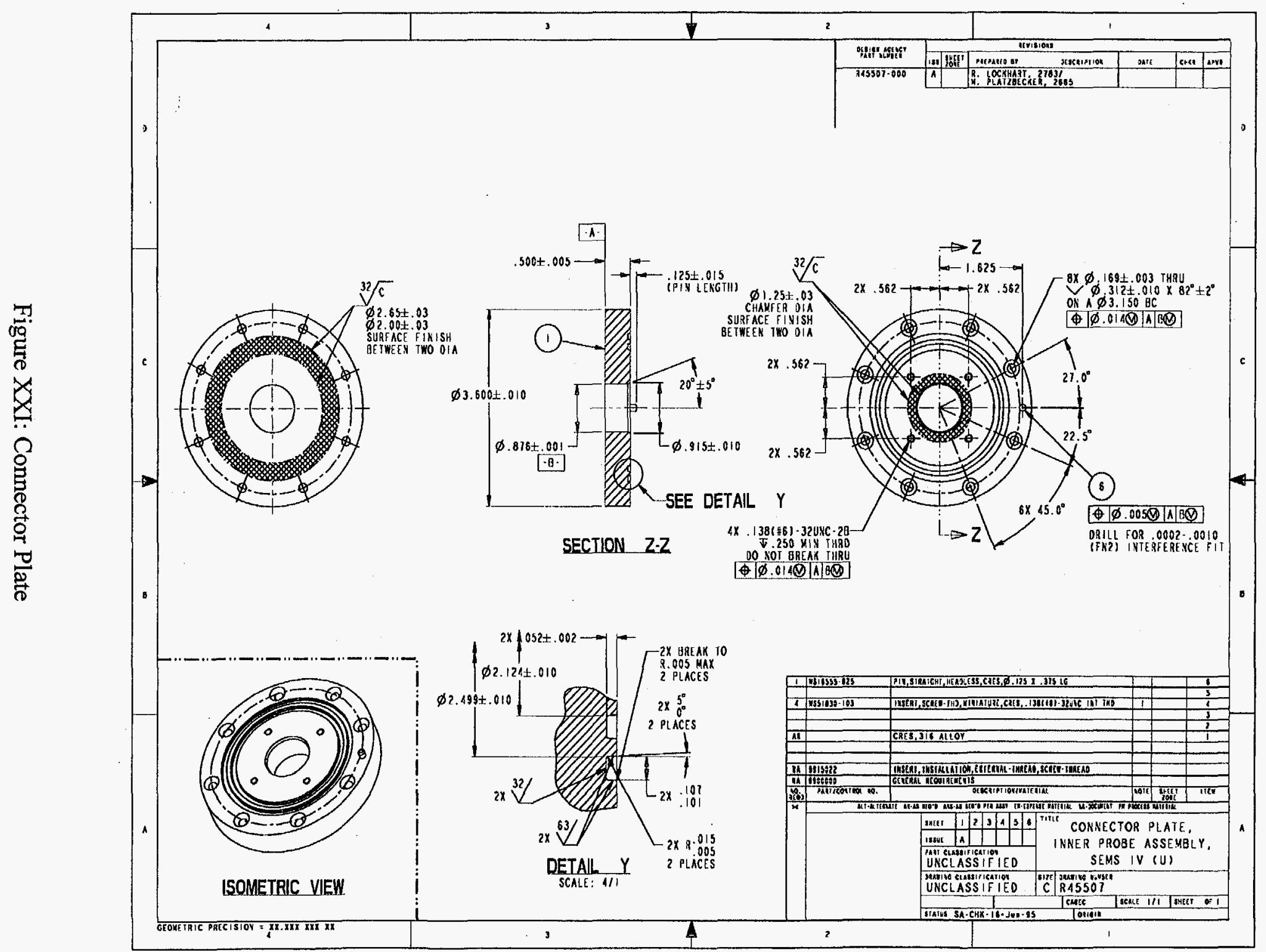




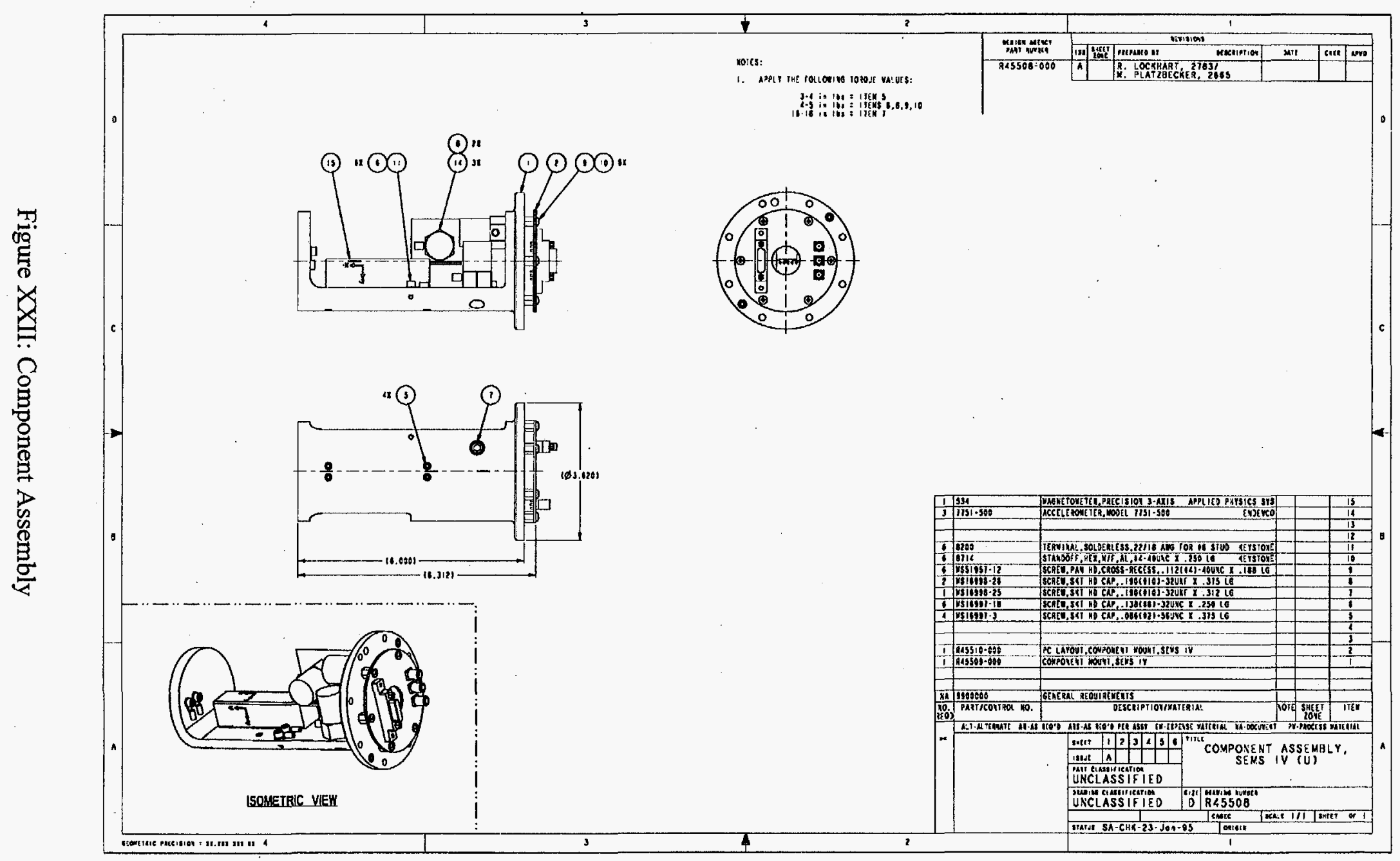




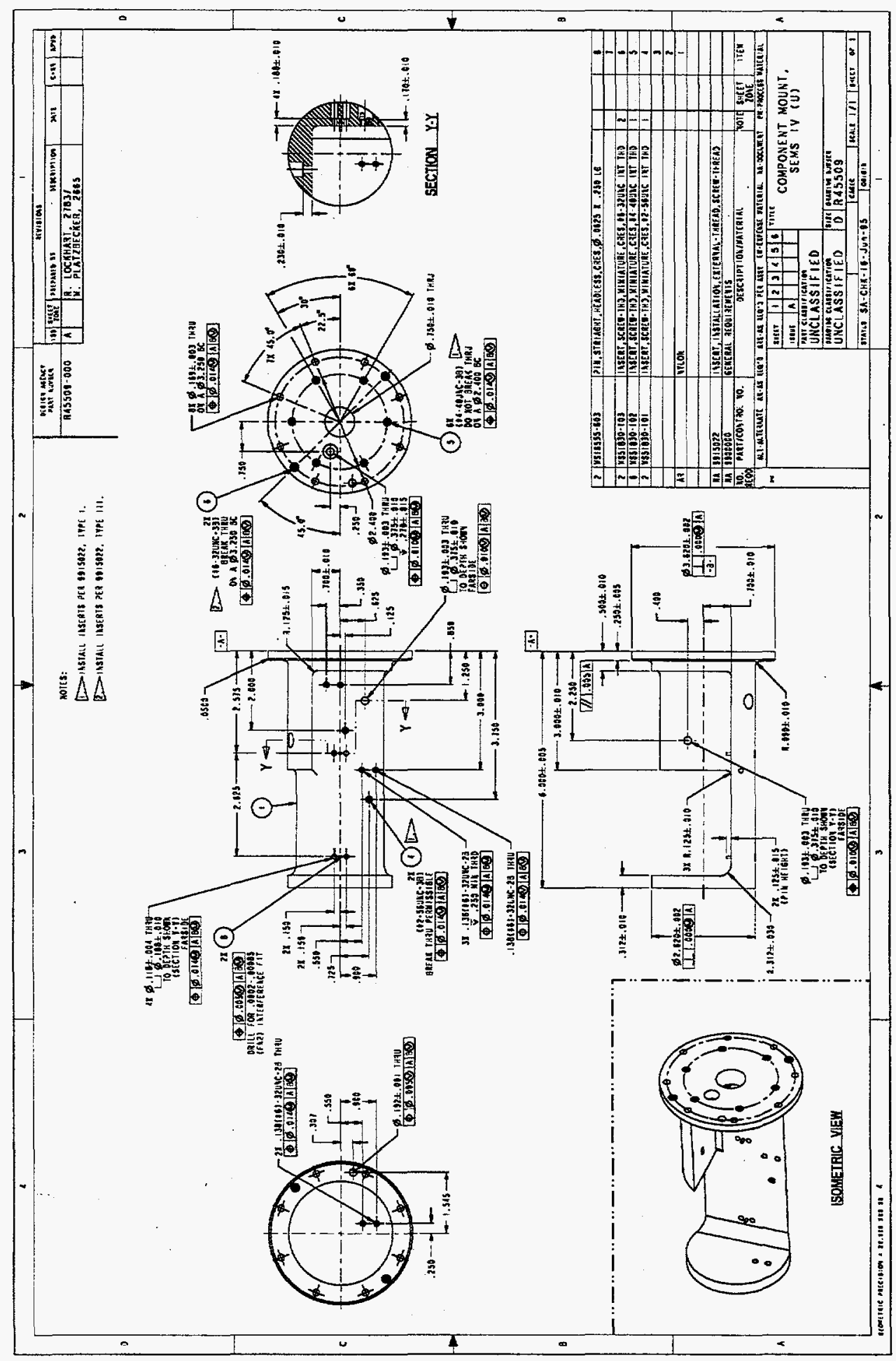

Figure XXIII: Component Mount 


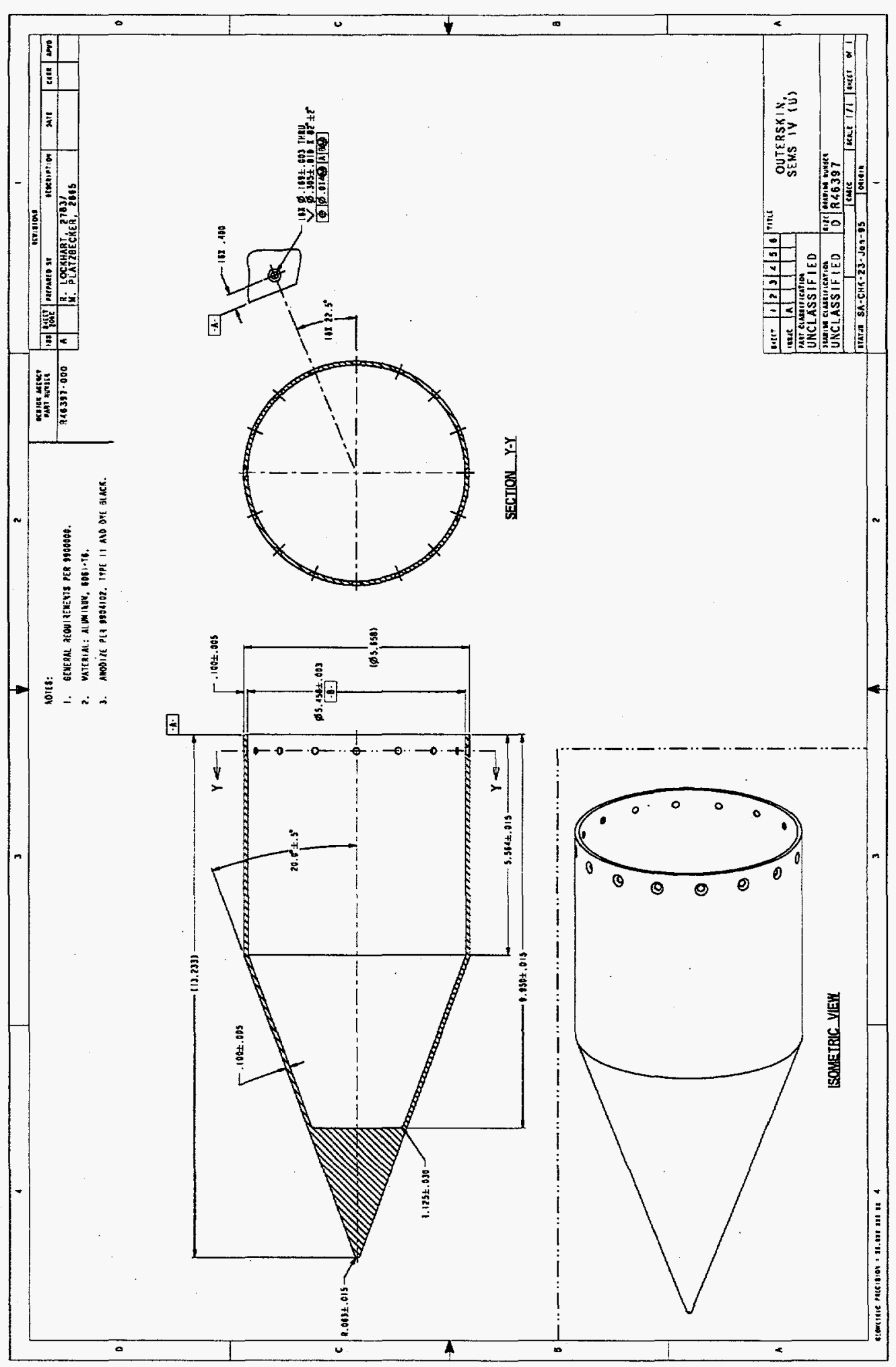

Figure XXIV: Outerskin 


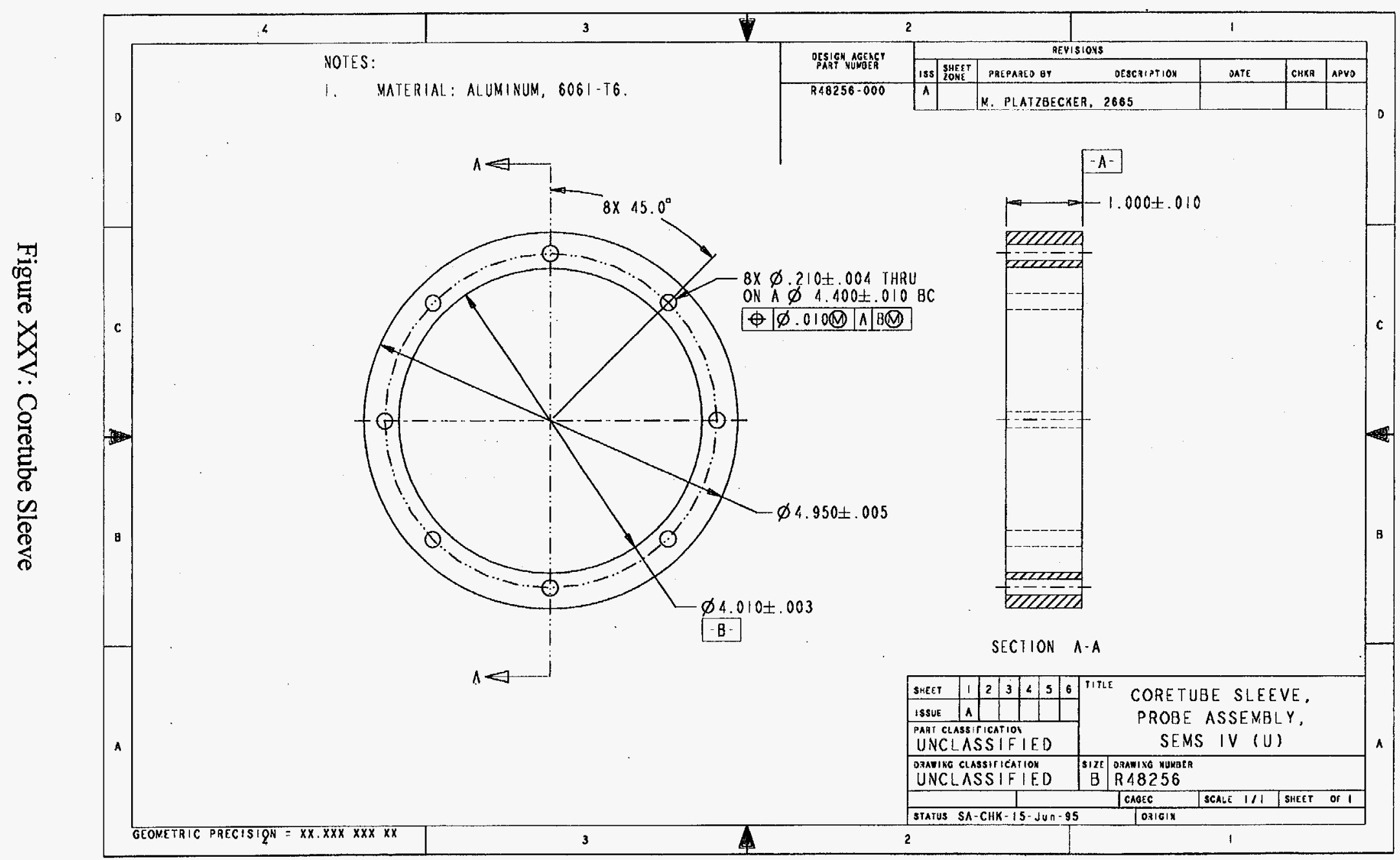




\section{IX.3 Appendix C. Navigation Plots}

Appendix $C$ includes navigation plots of all four probe locations. Personnel onboard the ship generated these plots after each of the probe installations. These plots depict the oil platform location and show all lines running in and out of the platforms. They also show the cable route from probe location to where it entered the J-tubes.

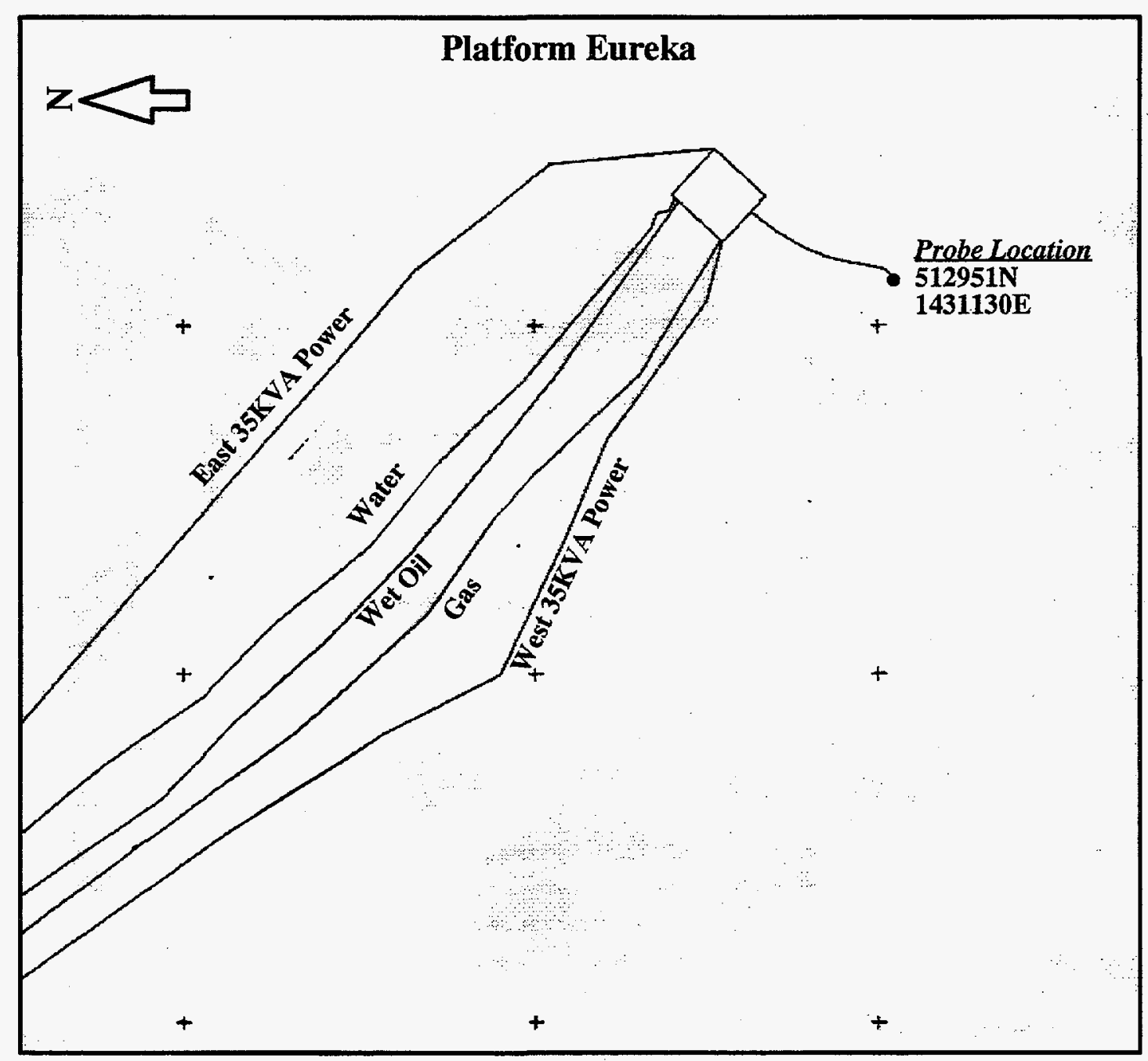

Figure XXVI: Eureka Navigation Plots 


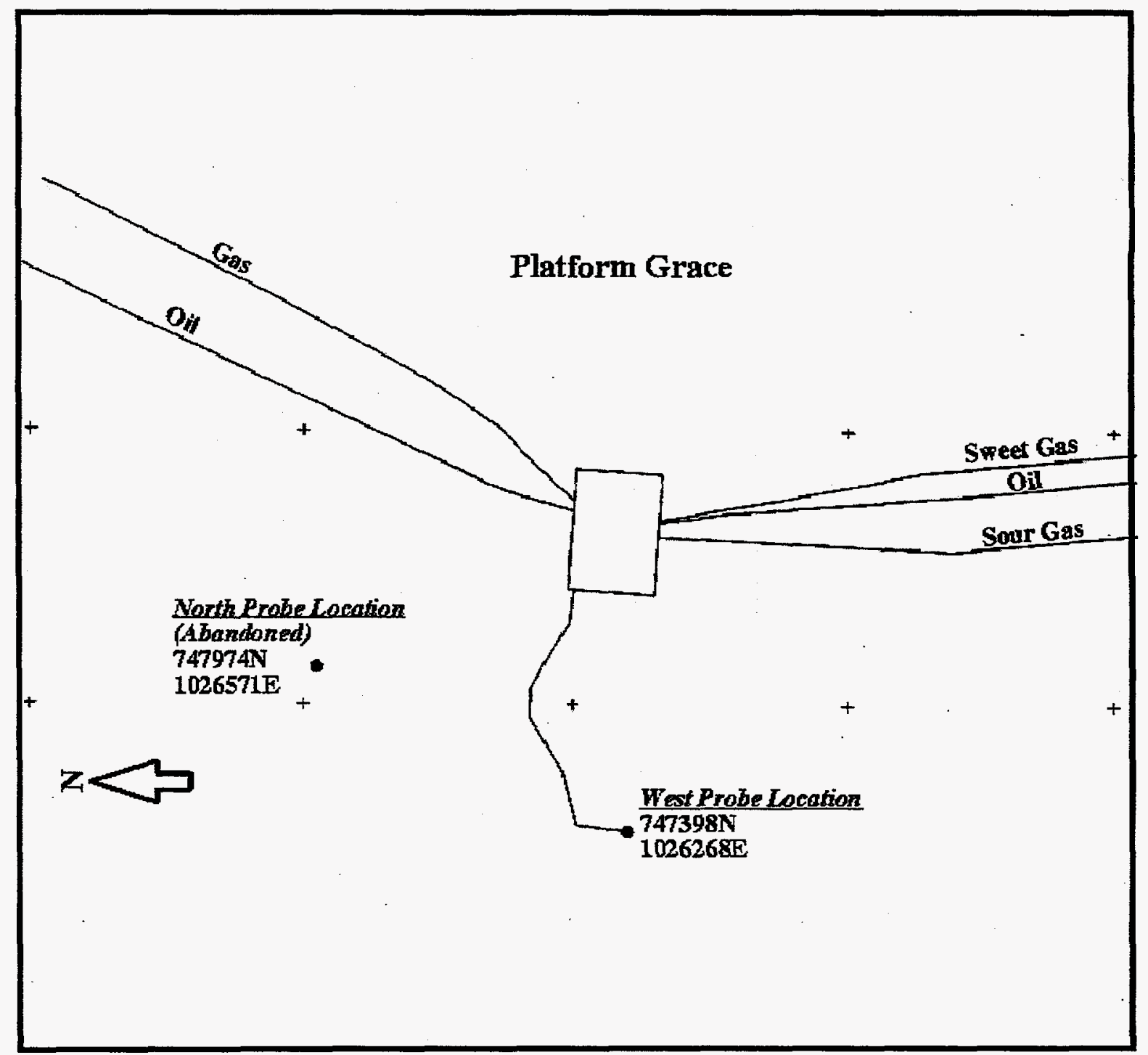

Figure XXVII: Grace Navigation Plots 


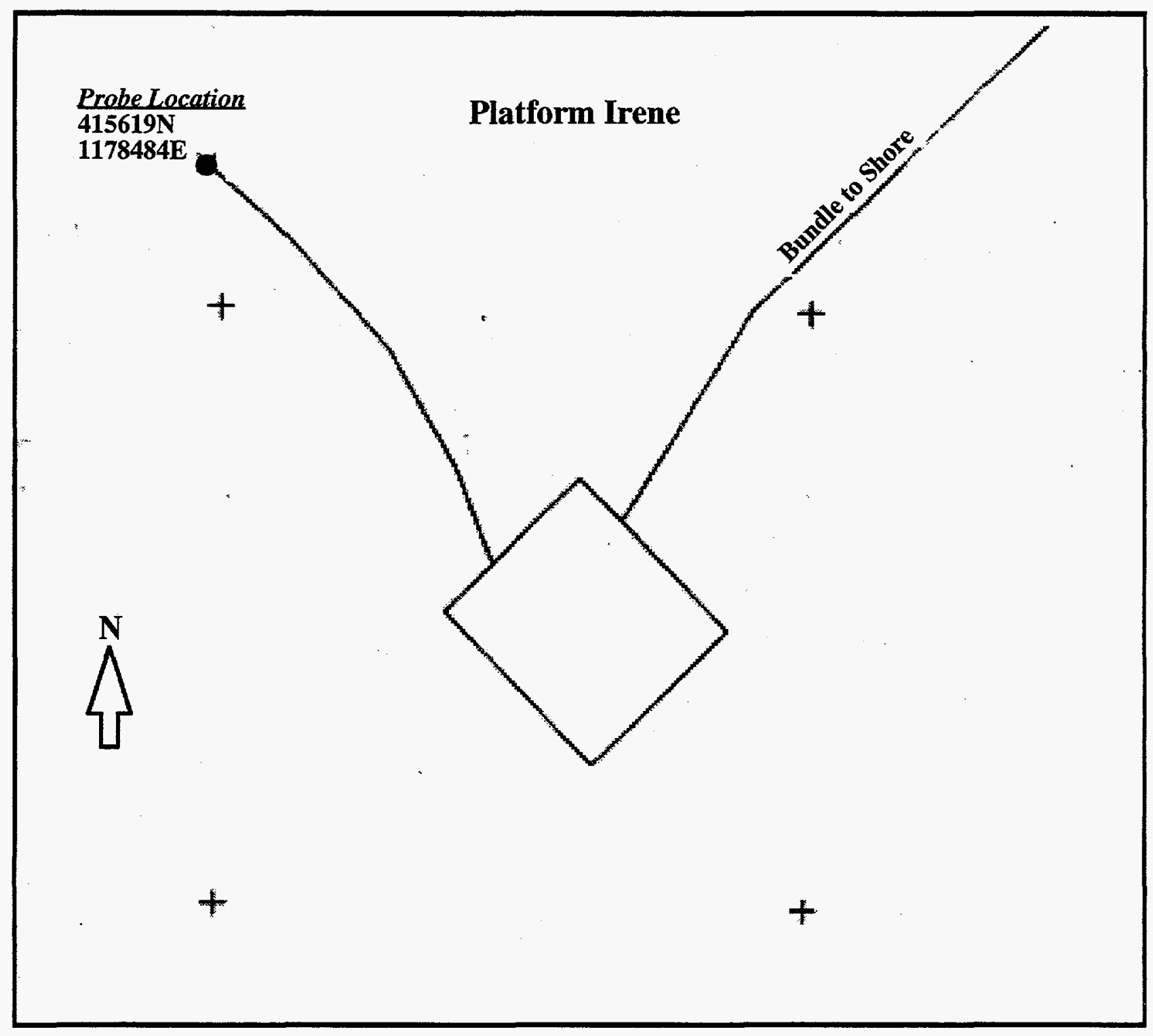

Figure XXVIII: Irene Navigation Plots 


\section{IX.4 Appendix D. SEMS IV Operating Instructions}

\section{IX.4.1 SEMS IV State of Health Monitoring}

A sample dial up session below demonstrates how to inspect the platforms' state of health. Tables D.1,2,3 provide the nominal state of health readings to be expected from each platform.

\section{Operator Input:}

1. Connect PC to modem and Launch "PCSeed"

2. Choose Platform/Station (Eureka/Grace/Irene)

3. Select "Modem" Menu and Choose "Dial"

6. Select Function: "H"

7. Observations of state of health readings can be made from the screen. When done:

8. "Hit any Key to exit"

9. Select Function: "q" followed by " $y$ "

10. $\$$ (hit escape key)

11. Command? "q"

12. Choose "Modem" Menu and "Hang Up"

Computer/Platform

Response:

Station Selection Menu

Modem is initialized for Selected

Platform

Should hear modem tones

"Connect 19200"

Logon to Selected Platform done automatically

Quanterra response with

"Command?" prompt

"\$" prompt for OS9 shell

Menu for aqshell appears with "Select Function"

Real time State of Health Monitor Screen appears
Menu for aqshell returns: "Select Function"

"\$" OS9 prompt returns

"Command?" prompt return

"Normal Termination" message 
Table XXIII: Nominal State of Health Readings from Platform Eureka

\begin{tabular}{|c|c|c|c|}
\hline $\begin{array}{c}\text { Signal } \\
\text { Name }\end{array}$ & $\begin{array}{c}\text { Quanterra } \\
\text { Channel \# }\end{array}$ & $\begin{array}{c}\text { Nominal Quanterra } \\
\text { Reading (counts) }\end{array}$ & $\begin{array}{c}\text { Monitor Indication } \\
\text { (Engineering Units) }\end{array}$ \\
\hline +8V Monitor & $\mathrm{A} ; 10$ & 236 & $10.5 \mathrm{~V}$ \\
\hline -8V Monitor & $\mathrm{A} ; 11$ & 20 & $-10.5 \mathrm{~V}$ \\
\hline Probe Temperature & $\mathrm{A} ; 09$ & 104 & $39^{\circ} \mathrm{F}$ \\
\hline Humidity & $\mathrm{A} ; 17$ & 158 & $21 \% \mathrm{RH}$ \\
\hline Water Detect & $\mathrm{A} ; 18$ & 139 & $\mathrm{dry}$ \\
\hline Z Accel (Probe X) & $80 ; 1$ & $-3853(\mathrm{erratic})$ & $\mathrm{na}$ \\
\hline N Accel (Probe Y) & $80 ; 2$ & -355 & $\mathrm{na}$ \\
\hline E Accel (Probe Z) & $80 ; 3$ & 2075 & na \\
\hline Magnetometer X & $80 ; 4$ & $-3,603,179$ & $-4.295 \mathrm{~V}$ \\
\hline Magnetometer Y & $80 ; 5$ & $-1,582,176$ & $1.886 \mathrm{~V}$ \\
\hline Magnetometer $Z$ & $80 ; 6$ & $-1,618,569$ & $-1.929 \mathrm{~V}$ \\
\hline & & & \\
\hline
\end{tabular}


Table XXIV: Nominal State-of-Health Readings from Platform Grace

\begin{tabular}{|c|c|c|c|}
\hline $\begin{array}{c}\text { Signal } \\
\text { Name }\end{array}$ & $\begin{array}{c}\text { Quanterra } \\
\text { Channel \# }\end{array}$ & $\begin{array}{c}\text { Nominal Quanterra } \\
\text { Reading (counts) }\end{array}$ & $\begin{array}{c}\text { Monitor Indication } \\
\text { (Engineering Units) }\end{array}$ \\
\hline +8V Monitor & $\mathrm{A} ; 10$ & 236 & $10.5 \mathrm{~V}$ \\
\hline -8V Monitor & $\mathrm{A} ; 11$ & 109 & $-10.9 \mathrm{~V}$ \\
\hline Probe Temperature & $\mathrm{A} ; 09$ & 146 & 19 $\mathrm{F}$ \\
\hline Humidity & $\mathrm{A} ; 17$ & 139 & $\mathrm{dr}$ \\
\hline Water Detect & $\mathrm{A} ; 18$ & -1742 & $\mathrm{na}$ \\
\hline Z Accel (Probe X) & $80 ; 1$ & 42 & na \\
\hline N Accel (Probe Y) & $80 ; 2$ & 1867 & $-4.14 \mathrm{~V}$ \\
\hline E Accel (Probe Z) & $80 ; 3$ & $-3,473,154^{*}$ & $-1.63 \mathrm{~V}$ \\
\hline Magnetometer X & $80 ; 4$ & $1,367,449^{*}$ & $1.29 \mathrm{~V}$ \\
\hline Magnetometer Y & $80 ; 5$ & $1,082,214^{*}$ & \\
\hline Magnetometer Z & $80 ; 6$ & & \\
\hline
\end{tabular}

*Note: These indications are from previous platform readings of the magnetometer at Grace. 
Table XXV: Nominal State-of-Health Readings from Platform Irene

\begin{tabular}{|c|c|c|c|}
\hline $\begin{array}{c}\text { Signal } \\
\text { Name }\end{array}$ & $\begin{array}{c}\text { Quanterra } \\
\text { Channel \# }\end{array}$ & $\begin{array}{c}\text { Nominal Quanterra } \\
\text { Reading (counts) }\end{array}$ & $\begin{array}{c}\text { Monitor Indication } \\
\text { (Engineering Units) }\end{array}$ \\
\hline$+8 \mathrm{~V}$ Monitor & $\mathrm{A} ; 10$ & 234 & $10.3 \mathrm{~V}$ \\
\hline$-8 \mathrm{~V}$ Monitor & $\mathrm{A} ; 11$ & 22 & $-10.3 \mathrm{~V}$ \\
\hline Probe Temperature & $\mathrm{A} ; 09$ & 113 & $47^{\circ} \mathrm{F}$ \\
\hline Humidity & $\mathrm{A} ; 17$ & 148 & $6 \% \mathrm{RH}$ \\
\hline Water Detect & $\mathrm{A} ; 18$ & 139 & $\mathrm{dry}$ \\
\hline Z Accel (Probe X) & $80 ; 1$ & 1284 & $\mathrm{na}$ \\
\hline N Accel (Probe Y) & $80 ; 2$ & -355 & $\mathrm{na}$ \\
\hline E Accel (Probe Z) & $80 ; 3$ & 1301 & $-3.763 \mathrm{~V}$ \\
\hline Magnetometer X & $80 ; 4$ & $-3,157,345$ & $0.232 \mathrm{~V}$ \\
\hline Magnetometer Y & $80 ; 5$ & $-195,331$ & $-0.714 \mathrm{~V}$ \\
\hline Magnetometer Z & $80 ; 6$ & $-599,148$ & \\
\hline & & & \\
\hline
\end{tabular}




\section{IX.4.2 SEMS IV Event Data Down Loading}

A sample dial up session below demonstrates how to search for event data at the platforms and to down load event data through the modem link.

\section{Operator Input:}

1. . Repeat steps $1-4$ as above

2. Command? "e"

3. Enter Start Time and Stop Time as prompted

4. Command? "k"

5. Enter UTC Start and Stop Time as directed

6. Select "Convert" menu and follow prompts

7. Command ?"q"

8. Choose "Modem" menu and "Hang Up"

\section{Computer/Platform Response:}

Station selected, Quanterra logged onto as above "Command?" prompt from Quanterra

"Enter UTC Starting Date and Time"

List of events from specified time appears (Identify and note times of event of interest)

Enter UTC Starting (and stop) Date and Time

Event data is downloaded via "Kermit"

"Normal Termination" message 


\section{Appendix E. SEMS Accelerometer Orientations}

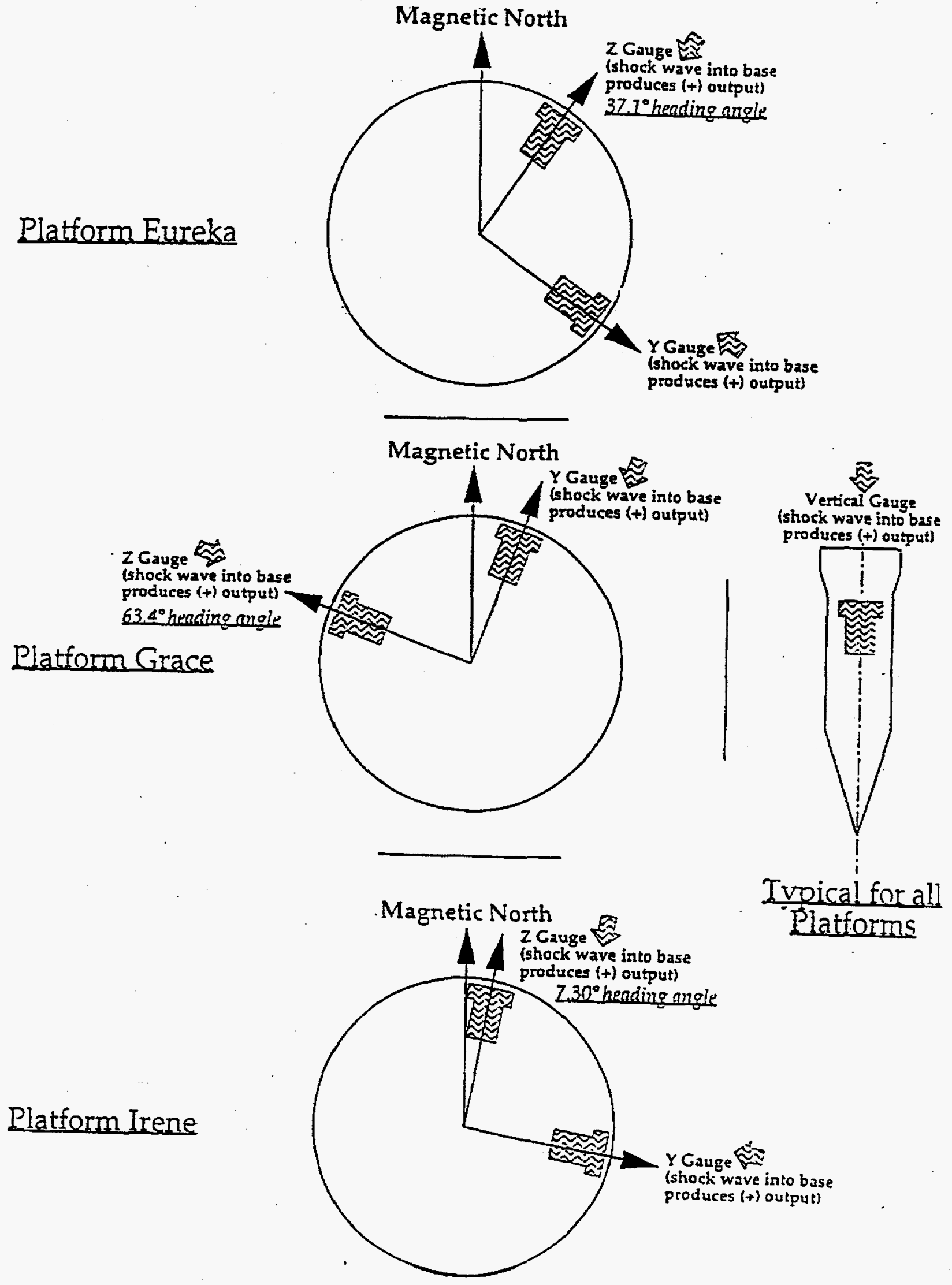

Figure XXIX: SEMS Accelerometer Orientation 


\section{Distribution:}

5 Charles Smith

U. S. Dept. of Interior

Mineral Management Service

Technology Assessment and

Research Branch

381 Elden Street, MS 4700

Herndon, VA 22071-4817

5 Cathy Hoffman

U. S. Dept. of Interior

Mineral Management Service

Pacific OCS Region

770 Paseo Camarillo

Camarillo, CA 93010

1 Leslie Monahan

U. S. Dept. of Interior

Mineral Management Service

Gulf of Mexico Region

1201 Elmwood Park Blvd:, MS

5210

New Orleans, LA 70123

2 Ted Roche

American Pacific Marine

741 East Arcturus Avenue

Oxnard, CA 93033

3 Anthony F. Shakal, Ph.D.

Office of Strong Motion Studies

$801 \mathrm{~K}$ Street, MS 13-35

Sacramento, CA 95814-3531
1 MS0985

1 MS0986

1 MS0987

$5 \quad$ MS0987

1 MS0987

$5 \quad$ MS0987

1 MS9018

5 MS0899

2 MS0619
John H. Stichman, 2600

Tom R. Perea, 2665

David E. Ryerson, 2664

Joseph P. Ehasz, 2664

Ronald J. Franco, 2664

Mark R. Platzbecker, 2664

Central Technical Files, 8940-2

Technical Library, 4916

Review \& Approval Desk, 12690

for DOE/OSTI 